\title{
Prediction of Surface Roughness and Optimization of Cutting Parameters of Stainless Steel Turning Based on RSM
}

\author{
Maohua Xiao (D), ${ }^{1,2}$ Xiaojie Shen,, You Ma, ${ }^{1}$ Fei Yang, ${ }^{1}$ Nong Gao, \\ Weihua Wei, ${ }^{3}$ and Dan Wu ${ }^{1}$ \\ ${ }^{1}$ College of Engineering, Nanjing Agricultural University, Nanjing 210031, China \\ ${ }^{2}$ Faculty of Engineering and the Environment, University of Southampton, SO17 1BJ, UK \\ ${ }^{3}$ College of Mechanical and Electronic Engineering, Nanjing Forestry University, Nanjing 210037, China
}

Correspondence should be addressed to Maohua Xiao; xiaomaohua@njau.edu.cn

Received 3 April 2018; Revised 18 June 2018; Accepted 19 July 2018; Published 2 August 2018

Academic Editor: Mohammed Nouari

Copyright (C) 2018 Maohua Xiao et al. This is an open access article distributed under the Creative Commons Attribution License, which permits unrestricted use, distribution, and reproduction in any medium, provided the original work is properly cited.

\begin{abstract}
The turning test of stainless steel was carried out by using the central composite surface design of response surface method (RSM) and Taguchi design method of central combination design. The influence of cutting parameters (cutting speed, feed rate, and cutting depth) on the surface roughness was analyzed. The surface roughness prediction model was established based on the second-order RSM. According to the test results, the regression coefficient was estimated by the least square method, and the regression equation was curve fitted. Meanwhile, the significance analysis was conducted to test the fitting degree and response surface design and analysis, in addition to establishing a response surface map and three-dimensional surface map. The life of the machining tool was analyzed based on the optimized parameters. The results show that the influence of feed rate on the surface roughness is very significant. Cutting depth is the second, and the influence of cutting speed is the least. Therefore, the cutting parameters are optimized and tool life is analyzed to realize the efficient and economical cutting of difficult-to-process materials under the premise of ensuring the processing quality.
\end{abstract}

\section{Introduction}

Surface quality is an important measure of the quality of machining, while surface roughness is one of the most important and basic parameters. It has a very important influence on the performance and service life of machinery and instruments $[1,2]$. The surface roughness of mechanical parts not only affects the actual effects of the cooperation between parts, working accuracy, but also is closely related to the physical properties and chemical properties, such as thermal conductivity, electrical conductivity, stress, fatigue, and corrosion, in particular, the key parts of aerospace vehicles, the sealing, fatigue resistance, and corrosion resistance, which have higher requirements on the roughness [3]. As the widely used metal in medical, metallurgy, shipbuilding, aerospace, and other fields, stainless steel has excellent properties such as good toughness, stress corrosion resistance, fatigue resistance, and fracture toughness [4]. In this paper, typical stainless steel $1 \mathrm{Cr} 18 \mathrm{Ni} 9 \mathrm{Ti}$ is the experimental object; its performance is shown in Table 1. Due to the severe plastic deformation and hardening during the processing of stainless steel, a large amount of heat is generated, and the chips are easily adhered to the tool to form (BUE), which seriously affects the surface roughness of the machined surface. In addition, stainless steel chips are not easily curled and broken, resulting in secondary damage to the processed surface, affecting the quality of the machined surface. In the actual production and processing, machining process parameters such as cutting speed, feed rate, and cutting depth will directly affect the surface roughness of the part. The part surface quality is improved by optimizing the cutting parameters being widely used [5].

At present, there are mainly the following methods for predicting the quality of surface processing: processing theoretical analysis, experimental analysis, empirical analysis, and algorithm analysis. 
TABLE 1: Characteristic of 1Cr18Ni9Ti.

\begin{tabular}{lccccc}
\hline 1Cr18Ni9Ti & $\begin{array}{c}\text { Mechanical properties } \\
\text { Hardness } \\
(\mathrm{HB})\end{array}$ & $\begin{array}{c}\text { Strength } \\
(\mathrm{Gpa})\end{array}$ & $\begin{array}{c}\text { Plasticity } \\
(\delta \%)\end{array}$ & $\begin{array}{c}\text { Impact toughness } \\
\left(\mathrm{ak} / \mathrm{m}^{2}\right)\end{array}$ & $\begin{array}{c}\text { Thermal } \\
\text { Conductivity } \\
(\mathrm{Rw} / \mathrm{m})\end{array}$ \\
\hline Grade & 229 & 0.642 & 55 & 2.45 & 16.3 \\
Grade of cutting process & 4 & 3 & 8 & 8 & 8 \\
Machinability & Easier & Easier & Difficult & Difficult & Difficult \\
\hline
\end{tabular}

Researches of surface topography based on machining theory mainly emphasize dynamics in machining process, parameters of machining tool, chip forming mechanism [6], and so on. Texture superposition method is used to predict texture of milled surfaces (Kim and Chu [7]). The surface morphology of the machine workpiece depends on the maximum residual height due to tool eccentricity, and the maximum residual height is determined by tool trace and default residual amount. Therefore, three-dimensional surface topography of workpiece can be obtained by superposition according to given cutting conditions and cutter types.

Machined surface quality prediction researches are conducted to analyze the surface roughness by collecting and analyzing experiment data. Verma et al. [8] used the Taguchi method in the end milling process to identify the variables having a major influence on surface finish. A nonparametric time series processing technique called the singular spectrum analysis is used to model vibration signals in order to forecast surface finish in precision end milling [9]; Hao et al. [6] make the prediction of surface roughness thin-walled parts processing model combine with many theoretical analyses at the same time considering the tool and other factors, making the model accuracy error of $12.4 \%$. At present, many researches focus on the prediction of surface quality using mathematical and algorithmic modeling. Lou et al. [10] adopted the statistical multiple regression technique to study the effect of variation of spindle speed, feed rate, and depth of cut on surface finish in the end milling of 6061 aluminum. Their proposed regression model predicted the surface roughness on the test data with an accuracy of $90.03 \%$.

Choi et al. [9] proposed a generalized model that can predict the surface roughness and burns of alumina grinding wheels during the grinding of cylindrical surfaces. Genetic algorithms, neural networks, fuzzy logic, and expert systems are the most commonly used methods in the study of surface quality analysis using intelligent algorithm analysis. Although these methods can better predict the surface quality of the workpiece, the modeling process is more complicated, and the calculation is also very cumbersome. Common BP neural networks such as that of Lu Zesheng et al. [11] are based on genetic algorithms to predict the roughness of ultraprecision cutting surface, the programming is more complicated, the operator has more parameters such as the crossover rate and mutation rate, and the choice of these parameters has a very significant impact on the quality of the solution. However, most of these choices are currently based on empirical choice; moreover, the disadvantage of modeling this algorithm is that it has a certain dependence on the initial population selection. Chen et al. [12] used neural network to establish a prediction model of the end milling surface roughness. They analyzed the effect of tool edge geometry on machined surface scallop heights and verified that the scallop height was decreasing by increasing the tool axis tilt angle. Yang et al. $[13,14]$ established a fuzzy networkbased surface roughness adaptive control system that can adapt to the cutting parameters. The system uses Kistler 9257B load cell dynamic measurement of milling force of the three orthogonal components and established a real-time monitoring method to improve the surface quality of the roughness of the milling. Issam Abu-Mahfouz et al. [15] used surface roughness prediction using support vector machines as a classification problem. By using three feature extraction algorithms to determine and predict the optimal attribute set required for surface roughness, the success rate reached $81 \%$. Kalidass and Palanisamy [16] used regression and ANN models for predicting surface roughness measured during milling of AISI 304 steel using an uncoated carbide end mill cutter. They found that the ANN model was capable of better predictions of surface roughness than the regression model. Jin et al. $[17,18]$ work is based on artificial neural network prediction algorithm of micromilling roughness model, using BP neural network algorithm; BP network structure is more complex and requires a lot of time and data training to ensure that the model predicted accuracy. This paper uses DCM Montgomery's methodology (RSM) that is a combination of mathematical and statistical principles of nonlinear regression for modeling and analysis of a number of independent variables affecting an independent response to a class of problems [19]. The empirical formula model is adopted to approximate the relationship between input and output. This empirical model is often used to express the development law of some things or to describe the corresponding theories in the field of engineering scientific computing. In this paper, the prediction of the roughness of the machined surface is tackled. When the model is researched, many variables include the processing parameters such as feed rate, depth of cut, and cutting speed. The correspondingly formed surface roughness is an independent response.

\section{Experimental Program and Design}

2.1. Central Composite Design. The most common method for creating a quadratic model of a response surface is the central composite design (CCD). The entire experiment is composed of three parts: a cube point (each coordinate is 1 or -1 ), a central point (coordinate 0 : the number is determined 


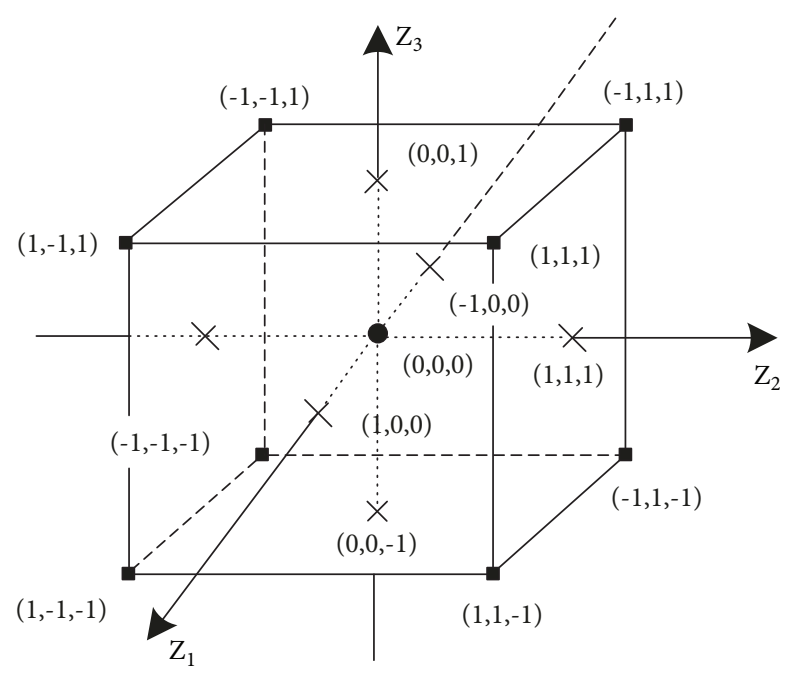

Figure 1: Central composite surface design.

as required), and asterisk points (except for a coordinate $+\alpha$ or $-\alpha$, the other coordinates are 0 , and the number is equal to twice the number of factors). A three-factor central composite design consists of a factor point, a central point, and an axial point; its type is central composite circumscribed design (CCC), central composite inscribed design (CCI), and central composite face-central design (CCF). In a typical CCD design, the number of levels of factors is five $(-\alpha,-1,0,1$, and $+\alpha$ ) while the number of levels of each of the CCF factors is three $(-1,0$, and 1$)$. Therefore, it is extremely meaningful in the case where the replacement level is difficult, and the CCF approach preserves coherence. The experimental results that have been performed on the previous cubic point can be used in the subsequent CCF design, so it can be used in secondorder regression. At the same time, CCF has the highest estimation accuracy of the interaction term in the model coefficient estimation and also ensures sufficient coefficient estimation accuracy for the linear term and the quadratic term. Therefore, this experiment uses the central composite surface design (CCF). The schematic diagram is shown in Figure 1.

2.2. Experimental Regression Model. When there are p variables, the general form of the quadratic regression equation is:

$$
\hat{y}=b_{0}+\sum_{j=1}^{k} b_{j} x_{j}+\sum_{i=1}^{k-1} \sum_{j=i+1}^{k} b_{i j} x_{i} x_{j}+\sum_{j=1}^{k} b_{j j} x_{j}^{2}
$$

Taking into account the cutting speed, feed rate and depth of cut will have an impact on the size of the surface roughness. Meanwhile, there are errors in the experiment and further to establish the cutting parameters on the surface roughness, the surface roughness of the quadratic regression equation was obtained:

$$
Y^{\prime}=R_{a}-\varepsilon=b_{0}+\sum_{i}^{k} b_{i} x_{i}+\sum_{i=1}^{k-1} \sum_{j=i+1}^{k} b_{i j} x_{i} x_{j}+\sum_{i=1}^{k} b_{i i} x_{i}^{2}
$$

where $R_{a}$ is the surface roughness; $Y^{\prime}$ is the surface roughness estimation; $\varepsilon$ is the test error; $b$ is the estimated value of the coefficient; $x$ is the processing parameter coding. $x_{j}$ is the $i$ component of the m-dimensional independent variable; $b_{0}, b_{i}, b_{i j}$ are the undetermined coefficients of the polynomial. In this paper, we arrange the undetermined coefficients in a certain order, which can form a vector $b$; we used $\mathrm{n}$ test points and the least square method to solve the vector $b$.

$$
\text { Where: } \mathrm{X}=\left[\begin{array}{cccc}
1 & x_{1}^{(1)} & L & x_{m-1}^{(n)} \\
M & M & M \\
1 & x_{1}^{(k)} & & x_{m-1}^{(k)} \\
M & M & M \\
1 & x_{1}^{(n)} & L & x_{m-1}^{(n)}
\end{array}\right] \text {, }
$$

$$
Y=\left[\begin{array}{c}
y^{(1)} \\
M \\
y^{(\mathrm{k})} \\
M \\
y^{(\mathrm{k})}
\end{array}\right]
$$

According to the choice of system response output and input variables in the paper, the polynomial model response surface can be expressed as

$$
\begin{aligned}
Y= & b_{0}+b_{1} x_{1}+b_{2} x_{2}+b_{3} x_{3}+b_{4} x_{1} x_{2}+b_{5} x_{1} x_{3} \\
& +b_{6} x_{2} x_{3}+b_{7} x_{1}{ }^{2}+b_{8} x_{2}{ }^{2}+b_{9} x_{3}^{2}
\end{aligned}
$$

The purpose of the experiment is to obtain a set of optimal stainless steel processing parameters in order to obtain the best stainless steel surface quality. However, it is often difficult to obtain the optimal processing parameters in actual production [11]. Therefore, this paper analyzes the impact of various factors on the response in the regression model; the inference and determination of the group level make the predicted value reach the optimal value.

2.3. Experimental Design. In machining, the cutting surface roughness mainly depends on the height of the cutting residual area, cutting speed, and cutting depth [20]. Factors that affect the height of the cutting residual area include tip radius, the main declination, declination, and feed [21]. However, the tool nose radius, the main declination angle, and the declination angle are all determined by the tool. Therefore, the cutting speed $(v)$, feed rate $(f)$, and cutting depth $\left(a_{p}\right)$ are the main cutting parameters that affect the roughness. Therefore, the experiment selected the above three kinds of cutting parameters as the influencing factor. This article is set to $\mathrm{X} 1, \mathrm{X} 2$, and $\mathrm{X} 3$ and divided into three horizontal design orthogonal experiments. Experimental machine equipment of Nanjing Agricultural University C6132A horizontal lathe was used; the tool material selection model is $41305 \mathrm{~A}$ carbide cutting insert, tool performance shown in Table 2. 
TABLE 2: Experimental mechanical properties of the tool material.

\begin{tabular}{lccccc}
\hline $\begin{array}{l}\text { Density } \\
\left(\mathrm{g} / \mathrm{cm}^{3}\right)\end{array}$ & $\begin{array}{c}\text { Hardness } \\
(\mathrm{HVA})\end{array}$ & $\begin{array}{c}\text { Flexural strength } \\
(\mathrm{MPa})\end{array}$ & $\begin{array}{c}\text { Impact toughness } \\
\left(\mathrm{MJ} \cdot \mathrm{m}^{-2}\right)\end{array}$ & $\begin{array}{c}\text { Thermal conductivity } \\
\left(\mathrm{K} \cdot \mathrm{m}^{-1} \cdot \mathrm{K}^{-1}\right)\end{array}$ & $\begin{array}{c}\text { Heat resistance } \\
\left({ }^{\circ} \mathrm{C}\right)\end{array}$ \\
\hline 14.7 & 90.0 & 2000 & 0.035 & 80 & 800 \\
\hline
\end{tabular}

The selected test workpiece material is ordinary stainless steel $1 \mathrm{Cr} 18 \mathrm{Ni} 9 \mathrm{Ti}$-chemical composition: $\mathrm{C} \leq 0.12 \%, \mathrm{Si} \leq 1 \%$, $\mathrm{Mn} \leq 2 \%, \mathrm{~S} \leq 0.03 \%, \mathrm{P} \leq 0.035 \%, \mathrm{Cr}(17 \%-19 \%), \mathrm{Ni}(8 \%-11 \%)$, and $\mathrm{TI}(5(\mathrm{C}-0.02)-0.8 \%)$. It belongs to austenitic material and is heat-treated at $920 \sim 1150^{\circ} \mathrm{C}$ by water quenching (solution treatment). Specific mechanical and cutting performance are shown in Table 1, with the workpiece surface roughness detection using JB-4C surface roughness step tester and the instrument based on GB/T10610-1998 national standards and ISO5436 and ISO11562 international standards for manufacturing. The measured parameters for the outline of the arithmetic mean deviation $R_{a}$.

2.4. Process of Experiment and Test Analysis. Assume that the cutting speed $v$ is $X_{1}$, the cutting depth $a_{p}$ is $X_{2}$, and the feed amount $f$ is $X_{3}$; meanwhile, the variation range of the processing parameters was determined: $v$ is $70-150(\mathrm{~m} / \mathrm{min})$, $a_{p}$ is $0.08-0.16(\mathrm{~mm})$, and $f$ is $0.20-0.60(\mathrm{~mm} / \mathrm{r}) . z_{1}, z_{0}$, and $z_{-1}$, respectively, represent the 1 level, 0 level, and -1 level of each processing parameter variable and encode the above three variables:

$$
x^{i}=\frac{z^{i}-z_{0 i}}{\Delta_{\mathrm{i}}}, \quad i=1,2,3
$$

In (5), $\mathrm{X}^{i}$ is the variable coding; $\mathrm{Z}^{i}$ is the processing parameter variable; $Z_{0 i}$ is the 0 level of the processing parameter variable; and $\Delta i$ is the range of variation, which can be calculated by $\Delta i=\left(\mathrm{Z}_{1 i}-\mathrm{Z}_{0 i}\right) / \mathrm{r}$ (in the CCF design, $r=1$ ). The horizontal coding of the processing parameters is shown in Table 3, finish turning for twenty times was conducted; the cutting process (a) and processing equipment (b-c) are shown in Figure 2. The tool material belongs to the YG class of China model; the model of the tool holder is T39W20G. In order to avoid the effect of tool wear on the experiment, we uniformly used 20 new tools (as in Figure 2(c)) of the same type for cutting experiments and measured each test surface roughness; the results are shown in Table 4.

2.4.1. Two Randomly Selected Test Images of JB-4C Surface Roughness Measuring Instrument. The surface roughness value was detected with cutting speed of $70 / 110(\mathrm{~m} / \mathrm{min})$, feed rate of $0.6 / 0.2(\mathrm{~mm} / \mathrm{r})$, and cutting depth of $0.08 / 0.12(\mathrm{~mm})$, respectively, by JB-4C surface roughness measuring instrument, and the roughness measurement method is a single measurement; the surface roughness values of 3.042/2.666 $(\mu \mathrm{m})$ are shown in Figures 3 and 4 . The above two sets of values are derived from twenty sets of experimental data, and the remaining complete data and corresponding code values are shown in Table 4. Meanwhile, in the above range, we did not find out the phase change of the material through the XRD test technology.
2.4.2. Taguchi Experimental Design. Taguchi design is an experimental design method focused on minimizing process variability or making products and processes least sensitive to environmental variability, which was created by Dr. Kenichi Taguchi, Japan. It enables the design of an optimized and stable model to test data results under variable environmental conditions [22]. Taguchi designs usually use orthogonal tables to design experiments and get more information by fewer tests. Therefore, $\mathrm{L}_{20}\left(4^{3}\right)$ orthogonal table was designed combined with the response surface design based on Taguchi experimental design. 20 in $\mathrm{L}_{20}\left(4^{3}\right)$ means that 20 tests are to be done, of which 3 means 3 factors and 1 to 4 mean 4 levels. The processing parameters and experimental level are shown in Table 3. The above two methods combined with the design of the form in Table 4.

\section{Experimental Results of the Analysis and Discussion}

3.1. Experimental Results Analysis. The free variables and surface roughness of each experimental factor are converted into a matrix form through the conversion of experimental parameters; then the coefficient of (2) is obtained by Matlab software, and the multiple regression empirical formula between surface roughness and cutting parameters can be established simultaneously. The coefficient in (2) is obtained by the data from Table 4 and through second-order multiple regression.

$$
\begin{aligned}
Y^{\prime}= & 2.44001-0.02211087 x_{1}+10.202 x_{2} \\
& +4.11341 x_{3}+0.0195312 x_{1} x_{2} \\
& -0.00115625 x_{1} x_{3}+7.875 x_{2} x_{3}+7.71023 \\
& * 10^{-5} x_{1}{ }^{2}-59.7727 x_{2}{ }^{2}-4.67841 x_{3}{ }^{2}
\end{aligned}
$$

According to Table 4, the quadratic regression fitting curve of each factor to the surface roughness value was fitted by Matlab software, the regression equation of the single factor submodel is (7), and the Minitab was used to fit the curve diagram as shown in Figures 5-7:

$$
\begin{aligned}
& Y^{\prime}=2.73871+0.00310125 x_{1}-8.9375 * 10^{-6} x_{1}^{2} \\
& Y^{\prime}=1.851+18.36 x_{2}-71.6875 x_{2}^{2} \\
& Y^{\prime}=1.96-3.7825 x_{3}-4.2145 x_{3}^{2}
\end{aligned}
$$

3.2. Discussion. From the above fitting curve (Figures 5-7), response surface model, and surface map, it can be seen that surface roughness of stainless steel $1 \mathrm{Cr} 18 \mathrm{Ni}$ 9Ti decreases firstly and then increases with the cutting speed increases 
TABLE 3: Factor encoding and level table.

\begin{tabular}{lccc}
\hline Coding $X_{i}$ & $X_{1}(V) /(\mathrm{m} / \mathrm{min})$ & $X_{2}\left(a_{p}\right) /(\mathrm{mm})$ & $X_{3}(f) /(\mathrm{mm} / \mathrm{r})$ \\
\hline 1 & 150 & 0.16 & 0.60 \\
0 & 110 & 0.12 & 0.40 \\
-1 & 70 & 0.08 & 0.20 \\
\hline
\end{tabular}

TABLE 4: 1Cr18Ni9Ti cutting experimental results.

\begin{tabular}{|c|c|c|c|c|c|c|c|}
\hline Experiment number & $\mathrm{X}_{1}$ & $\mathrm{X}_{2}$ & $\mathrm{X}_{3}$ & $\mathrm{X}_{1}(\mathrm{~V}) /(\mathrm{m} / \mathrm{min})$ & $\mathrm{X}_{2}\left(\mathrm{a}_{\mathrm{p}}\right) /(\mathrm{mm})$ & $\mathrm{X}_{3}(\mathrm{f}) /(\mathrm{mm} / \mathrm{r})$ & $\mathrm{R}_{\mathrm{a}} /(\mu \mathrm{m})$ \\
\hline 1 & 1 & 1 & 1 & 150 & 0.16 & 0.6 & 3.276 \\
\hline 2 & 1 & 1 & -1 & 150 & 0.16 & 0.2 & 2.706 \\
\hline 3 & 1 & -1 & 1 & 150 & 0.08 & 0.6 & 3.083 \\
\hline 4 & 1 & -1 & -1 & 150 & 0.08 & 0.2 & 2.694 \\
\hline 5 & -1 & 1 & 1 & 70 & 0.16 & 0.6 & 3.181 \\
\hline 6 & -1 & 1 & -1 & 70 & 0.16 & 0.2 & 2.503 \\
\hline 7 & -1 & -1 & 1 & 70 & 0.08 & 0.6 & 3.042 \\
\hline 8 & -1 & -1 & -1 & 70 & 0.08 & 0.2 & 2.687 \\
\hline 9 & 1 & 0 & 0 & 150 & 0.12 & 0.4 & 3.255 \\
\hline 10 & -1 & 0 & 0 & 70 & 0.12 & 0.4 & 3.147 \\
\hline 11 & 0 & 1 & 0 & 110 & 0.16 & 0.4 & 3.101 \\
\hline 12 & 0 & -1 & 0 & 110 & 0.08 & 0.4 & 2.799 \\
\hline 13 & 0 & 0 & 1 & 110 & 0.12 & 0.6 & 3.051 \\
\hline 14 & 0 & 0 & -1 & 110 & 0.12 & 0.2 & 2.666 \\
\hline 15 & 0 & 0 & 0 & 110 & 0.12 & 0.4 & 3.029 \\
\hline 16 & 0 & 0 & 0 & 110 & 0.12 & 0.4 & 3.010 \\
\hline 17 & 0 & 0 & 0 & 110 & 0.12 & 0.4 & 2.991 \\
\hline 18 & 0 & 0 & 0 & 110 & 0.12 & 0.4 & 3.029 \\
\hline 19 & 0 & 0 & 0 & 110 & 0.12 & 0.4 & 3.019 \\
\hline 20 & 0 & 0 & 0 & 110 & 0.12 & 0.4 & 3.022 \\
\hline
\end{tabular}

(as shown in Figure 8). It can get a better surface roughness value if we meet a certain cutting speed; the surface roughness begins to increase again when the cutting speed exceeds a certain speed value. Due to the low cutting temperature at low speeds ( $30 \mathrm{~m} / \mathrm{min}-90 \mathrm{~m} / \mathrm{min}$ ), the stainless steel material adheres to the surface of the tool to form built-up edge, and the surface of the workpiece has obvious tearing and bursting, resulting in increased surface roughness. When the cutting speed is about $110 \mathrm{~m} / \mathrm{min}$, with the increase of cutting temperature, the material will have obvious softening effect, the built-up edge will disappear, the surface of the workpiece will be smooth, and the roughness value will become smaller. With the increase of cutting speed $(120 \mathrm{~m} / \mathrm{min}-140 \mathrm{~m} / \mathrm{min})$, the cutting temperature rises significantly, the situation that the mountain-like defects are raised at a uniform distance from the surface is very serious, and the workpiece surface material undergoes severe plastic deformation and lateral flow in the cutting process due to the influence of cutting force and cutting temperature. In addition, the wear of the back of the tool is intensified. In the shear separation process, part of the workpiece material on the machined surface is carried away by chips or part of the chips is stuck on the processed surface, and the phenomenon of sticking occurs, resulting in a large roughness. However, the influence of feed rate on the surface roughness is very large. The surface roughness increases due to the increase of the feed rate leading to a proportional increase of the residual area of the machined surface (Figure 9). Because the feed rate affects the size of the residual surface area of the workpiece surface, it directly affects the size of the surface roughness. The increase in the feed rate leads to an increase in the residual area of the cutting and increases the roughness (Also including $R_{z}, R_{p}$, and $R_{v}$ ). Cutting depth has a smaller effect on the surface roughness of the stainless steel, with a slight increase in surface roughness as cutting depth increases (Figure 10). As the depth of cut increases, the surface roughness of the part being machined increases. As the depth of cut increases, the cutting force of the cutting tool also increases, and the vibration of the tool system also increases. These factors make the part of the quality of the machined surface deteriorate. Therefore, in order to improve the surface quality of the parts, a smaller depth of cut should be used as far as possible to meet the processing requirements. Therefore, the combined effect of the three on the surface roughness is that feed rate accounts for a large proportion. The R-Sq value of it reaches $78 \%$; the relationship between the cutting speed and roughness is more complicated; it reaches a better roughness near a certain value, so it presents a periodic change and provides a basis 


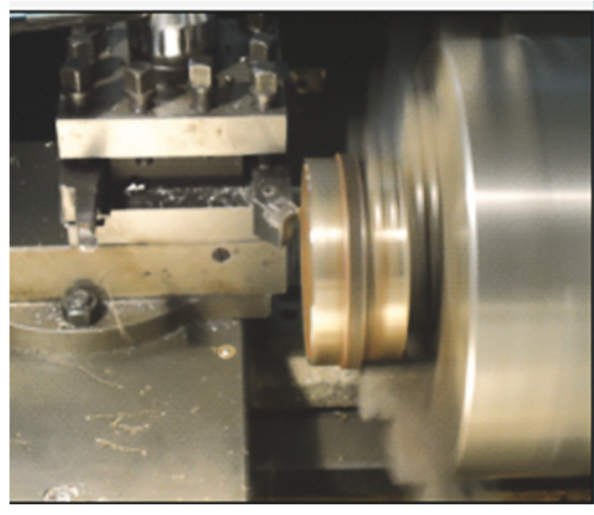

(a) 1 Cr18Ni9Ti process diagram

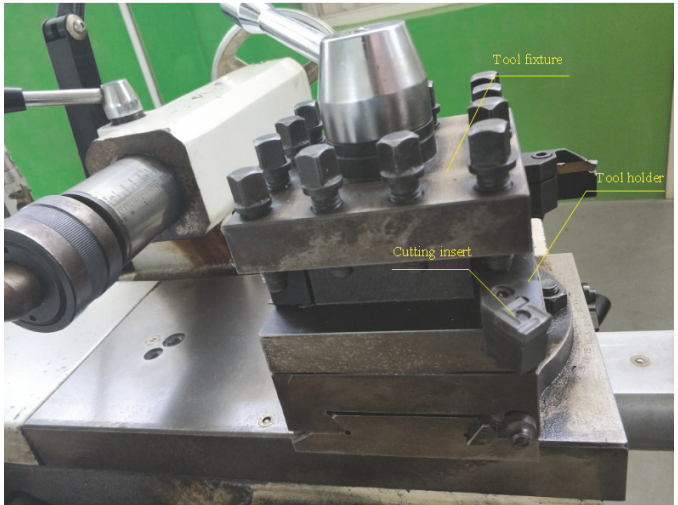

(b) Tool system

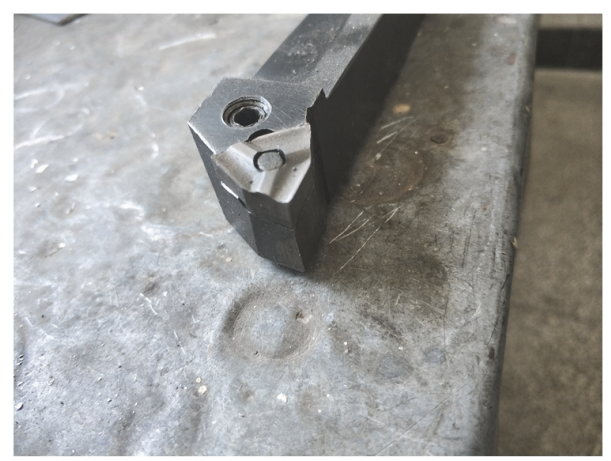

(c) Tool

FIGURE 2: Processing and processing equipment.

for optimizing the parameters below. Cutting depth has little effect on the roughness. At the same time the factors that affect the roughness model are obtained as follows:

$$
\begin{aligned}
Y^{\prime}= & 2.15114-0.02922 x_{1}+23.8784 x_{2} \\
& +0.0195312 x_{1} x_{2}-5.32422 * 10^{-5} x_{1}{ }^{2} \\
& -103.6 x_{2}{ }^{2} \\
Y^{\prime}= & 2.37689-0.0148337 x_{1}+5.77569 x_{3} \\
& -0.0011563 x_{1} x_{3}+7.46875 * 10^{-5} x_{1}{ }^{2} \\
& -5.58 x_{3}^{2} \\
Y^{\prime}= & 1.9598+3.61125 x_{2}+2.821 x_{3}+7.875 x_{2} x_{3} \\
& -23.3594 x_{2}{ }^{2}-3.22187 x_{3}{ }^{2}
\end{aligned}
$$

The effects of various factors on the surface roughness of 1Cr18Ni9Ti stainless steel were obtained: $f>a_{p}>v$.

\section{Optimization of Model and Verification of Reliability of Model}

4.1. Analysis and Verification of the Model. In order to get the optimal regression equation of the roughness model of $1 \mathrm{Cr} 18 \mathrm{Ni} 9 \mathrm{Ti}$, the linear term, the quadratic term, and the interaction term in (6) were analyzed by using Matlab software. The results are shown in Table 5 . If the item $P$ is less than or equal to 0.05 in the significance analysis, the item is significant [23]; otherwise, the item is not obvious. As shown in Table 5, the $P$ value of the linear term $\mathrm{X}_{3}$ is less than 0.001; it is quite significant; the proportion of the influence of feed rate on surface roughness is verified again. The $P$ values of linear term of $\mathrm{X}_{1}$ and $\mathrm{X}_{2}$ are less than 0.05 ; the quadratic terms $\mathrm{X}_{1}^{2}$, $\mathrm{X}_{2}{ }^{2}, \mathrm{X}_{3}{ }^{2}$ are significant $(P$ value $<0.05)$, and the $P$ values of interaction terms $X_{1}$ and $X_{2}, X_{1}$, and $X_{3}$ are greater than 0.05 , so the above two interaction terms (greater than 0.05) cannot be considered significant.

The insignificant term was removed in the significant analysis and the second-order response surface model (equation (6)) was modified, in order to optimize the model according to the principle of regression equation optimization. Finally, the response surface analysis model equation of 1Cr18Ni9Ti stainless steel surface roughness is obtained:

$$
\begin{aligned}
Y^{\prime}= & 2.44001-0.02211087 x_{1}+10.202 x_{2} \\
& +4.11341 x_{3}+7.875 x_{2} x_{3}+7.71023 * 10^{-5} x_{1}{ }^{2} \\
& -59.7727 x_{2}{ }^{2}-4.67841 x_{3}{ }^{2}
\end{aligned}
$$

From the normalized residual histogram of surface roughness in Figure 11, it can be seen that No. 3 point is an abnormal value of surface roughness. The standardized 


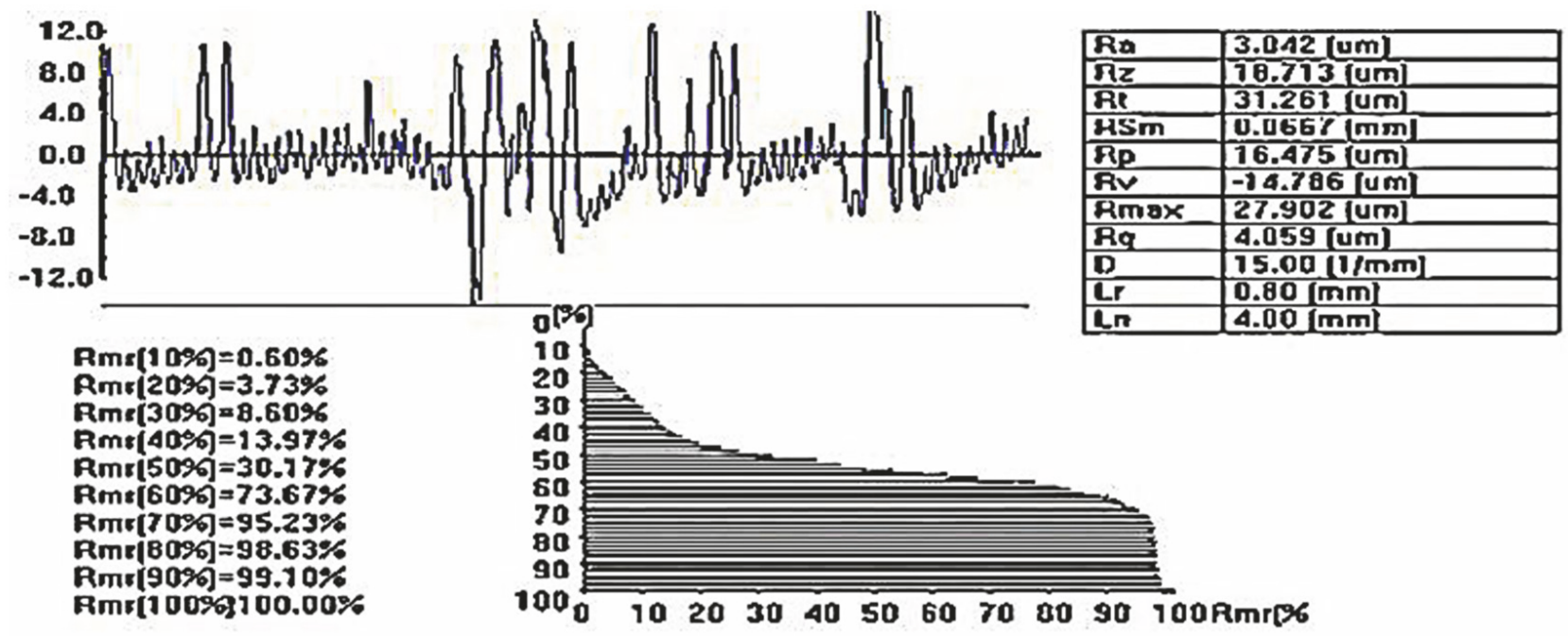

Figure 3: 1Cr18Ni9Ti: cutting speed $70 \mathrm{~m} / \mathrm{min}$, cutting depth $0.08 \mathrm{~mm} / \mathrm{r}$, and feed rate $0.60 \mathrm{~mm}$.

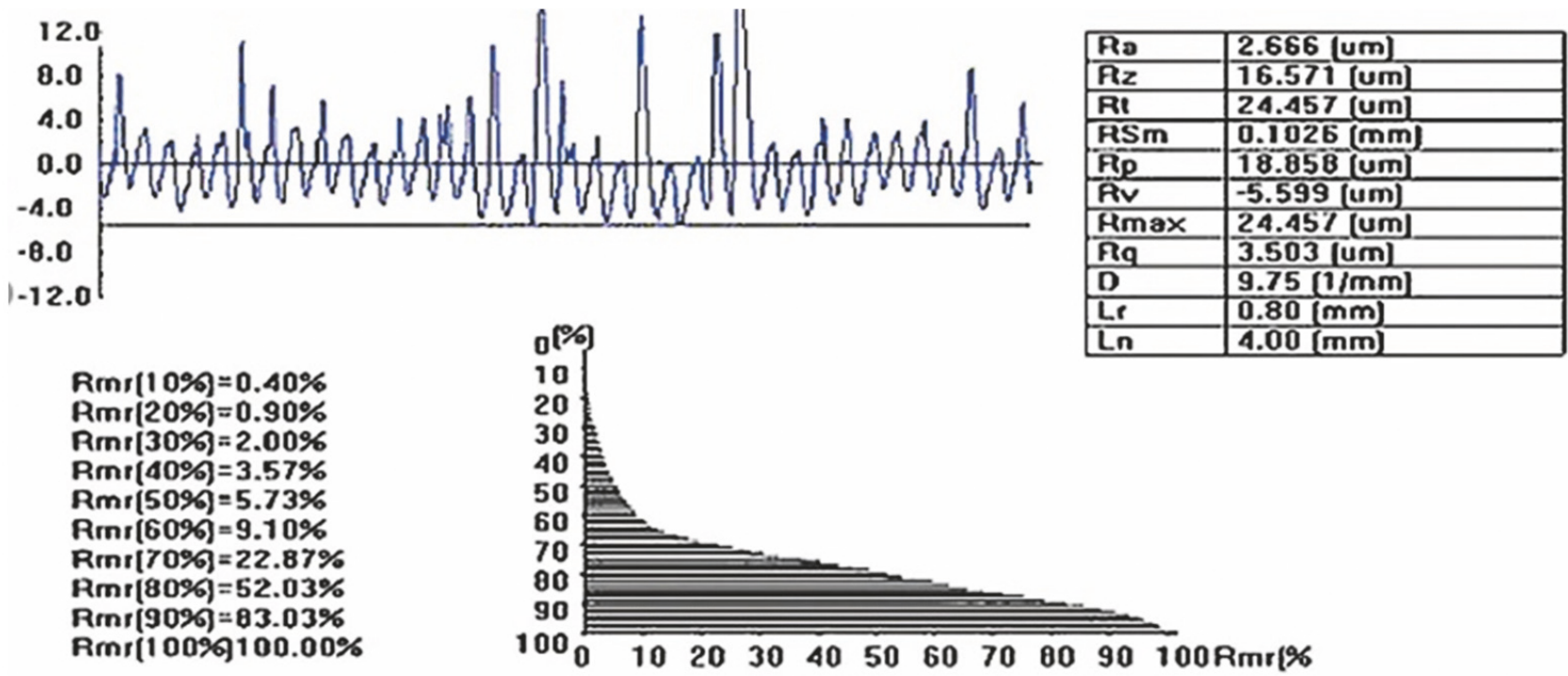

Figure 4: 1Cr18Ni9Ti: cutting speed $110 \mathrm{~m} / \mathrm{min}$, cutting depth $0.12 \mathrm{~mm} / \mathrm{r}$, and feed rate $0.20 \mathrm{~mm}$.

TABLE 5: Analysis of the surface roughness of $1 \mathrm{Cr} 18 \mathrm{Ni} 9 \mathrm{Ti}$ and the significance of various factors.

\begin{tabular}{|c|c|c|c|c|c|}
\hline Source & Degree of freedom & SS & MS & $\mathrm{F}$ & $\mathrm{P}$ \\
\hline Model & 9 & 0.832526 & 0.092503 & 23.67 & 0.000 \\
\hline Linear & 3 & 0.606969 & 0.202323 & 51.77 & 0.000 \\
\hline $\mathrm{X}_{1}$ & 1 & 0.020612 & 0.020612 & 5.27 & 0.045 \\
\hline $\mathrm{X}_{2}$ & 1 & 0.09526 & 0.095258 & 5.46 & 0.042 \\
\hline $\mathrm{X}_{3}$ & 1 & 0.565013 & 0.565013 & 144.57 & 0.000 \\
\hline Square & 3 & 0.185308 & 0.061769 & 15.81 & 0.000 \\
\hline $\mathrm{X}_{1} * \mathrm{X}_{1}$ & 1 & 0.066379 & 0.066379 & 16.98 & 0.002 \\
\hline $\mathrm{X}_{2} * \mathrm{X}_{2}$ & 1 & 0.25152 & 0.25152 & 6.44 & 0.030 \\
\hline $\mathrm{X}_{3} * \mathrm{X}_{3}$ & 1 & 0.096305 & 0.096305 & 24.64 & 0.001 \\
\hline 2-Way Interaction & 3 & 0.040249 & 0.040249 & 3.43 & 0.060 \\
\hline $\mathrm{X}_{1} * \mathrm{X}_{2}$ & 1 & 0.007812 & 0.007812 & 2.00 & 0.188 \\
\hline $\mathrm{X}_{1} * \mathrm{X}_{3}$ & 1 & 0.000684 & 0.000684 & 0.18 & 0.684 \\
\hline $\mathrm{X}_{2} * \mathrm{X}_{3}$ & 1 & 0.031752 & 0.031752 & 8.12 & 0.017 \\
\hline
\end{tabular}


TABLE 6: Experimental verification of model reliability.

\begin{tabular}{lcccccc}
\hline Serial number & $V(\mathrm{~m} / \mathrm{min})$ & $a_{p}(\mathrm{~mm})$ & $f(\mathrm{~mm} / \mathrm{r})$ & Roughness of test $(\mu \mathrm{m})$ & Predicted roughness $(\mu \mathrm{m})$ & Relative error/\% \\
\hline 1 & 75 & 0.09 & 0.3 & 2.836 & 2.675 & $6 \%$ \\
2 & 85 & 0.11 & 0.4 & 2.605 & 2.756 & 2.247 \\
3 & 92 & 0.12 & 0.2 & 2.121 & 2.380 & $5.5 \%$ \\
4 & 96 & 0.15 & 0.3 & 2.544 & 2.605 & $5.6 \%$ \\
5 & 113 & 0.1 & 0.6 & 2.748 & 2.599 & $5.5 \%$ \\
6 & 124 & 0.13 & 0.5 & 2.454 & 2.557 & $5.6 \%$ \\
7 & 143 & 0.14 & 0.6 & 2.38 & 2.53 & $6.9 \%$ \\
8 & 117 & 0.13 & 0.4 & 2.409 & 1.92 & $3.8 \%$ \\
9 & 112 & 0.16 & 0.2 & 1.89 & 2.596 & $7 \%$ \\
10 & 128 & 0.12 & 0.5 & 2.41 & & 3 \\
\hline
\end{tabular}

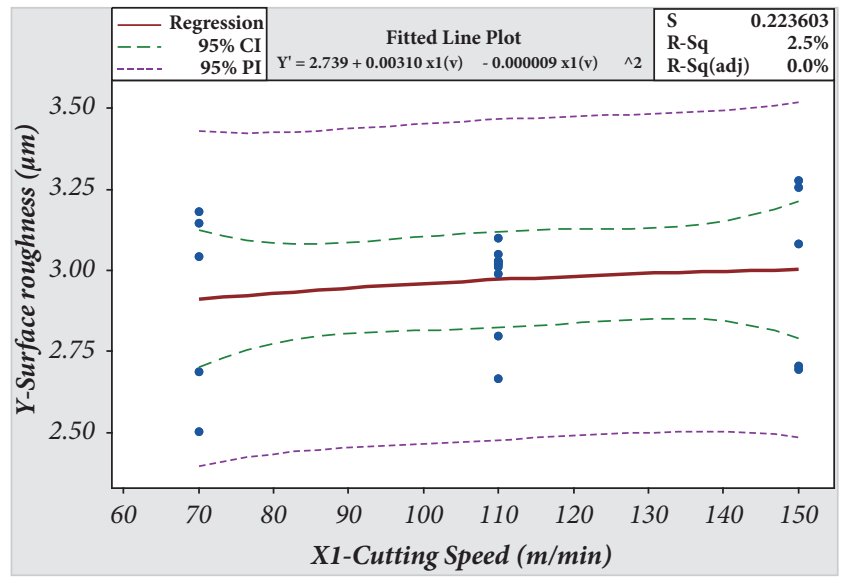

Figure 5: Fitting curve of surface roughness of $1 \mathrm{Cr} 18 \mathrm{Ni}$ Ti and cutting speed.

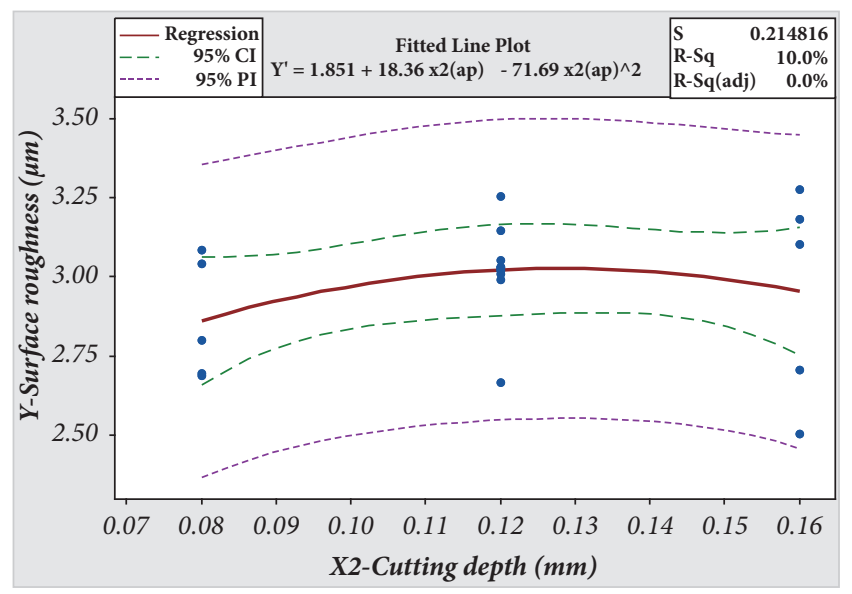

FIGURE 6: Fitting curve of surface roughness of $1 \mathrm{Cr} 18 \mathrm{Ni9Ti}$ and cutting depth.

residuals map basically shows a straight line, so the above reasoning is reasonable.

In order to ensure the reliability of the model being built, it is verified again by actual machining. $1 \mathrm{Cr} 18 \mathrm{Ni} 9 \mathrm{Ti}$ stainless steel was cut by random combination of process parameters

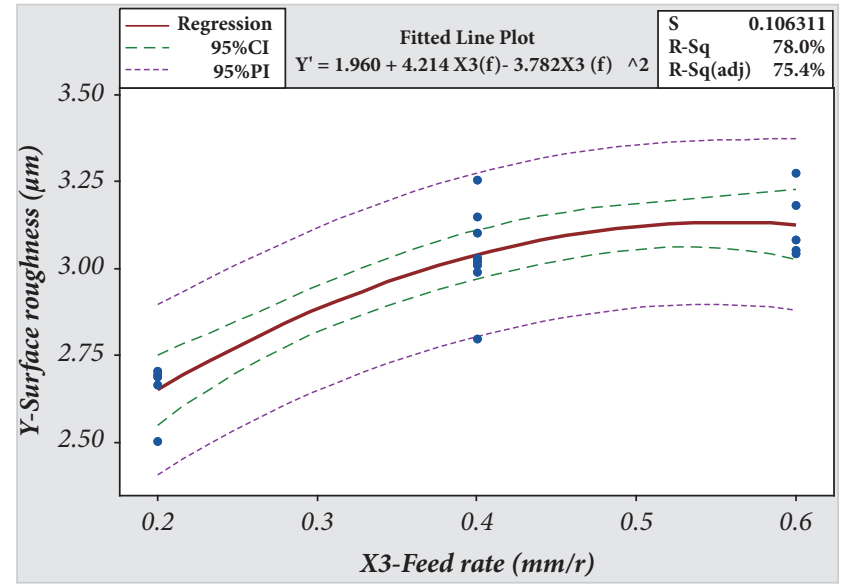

FIGURE 7: Fitting curve of surface roughness of $1 \mathrm{Cr} 18 \mathrm{Ni9Ti}$ and feed rate.

and compared with the surface roughness results obtained by the model analysis. The results are shown in Table 6. The experimental data in Table 6 show that the relative error between the actual roughness and the model analysis is less than $7 \%$, which verifies the reliability of the surface roughness analysis model.

The surface roughness value was detected with cutting speed of $85 / 92(\mathrm{~m} / \mathrm{min})$, feed rate of $0.4 / 0.2(\mathrm{~mm} / \mathrm{r})$, and cutting depth of $0.11 / 0.12(\mathrm{~mm})$, respectively, by JB-4C surface roughness measuring instrument, and the roughness measurement method is a single measurement; the surface roughness values of 2.605/2.121 $(\mu \mathrm{m})$ are shown in Figures 12 and 13 . Figures 12 and 13 correspond to the experimental results of No. 1 and No. 2 in Table 6.

4.2. Optimization of Test. Many kinds of processing parameters optimization goals are investigated, improving the quality of surface processing for the optimization of the target. Process parameters are optimized by using response surface methodology according to the requirements of the surface roughness, and the optimization is solved by using Minitab. In this experiment, the cutting speed, cutting depth, and feed speed were used as constraints (as shown in Table 7), 

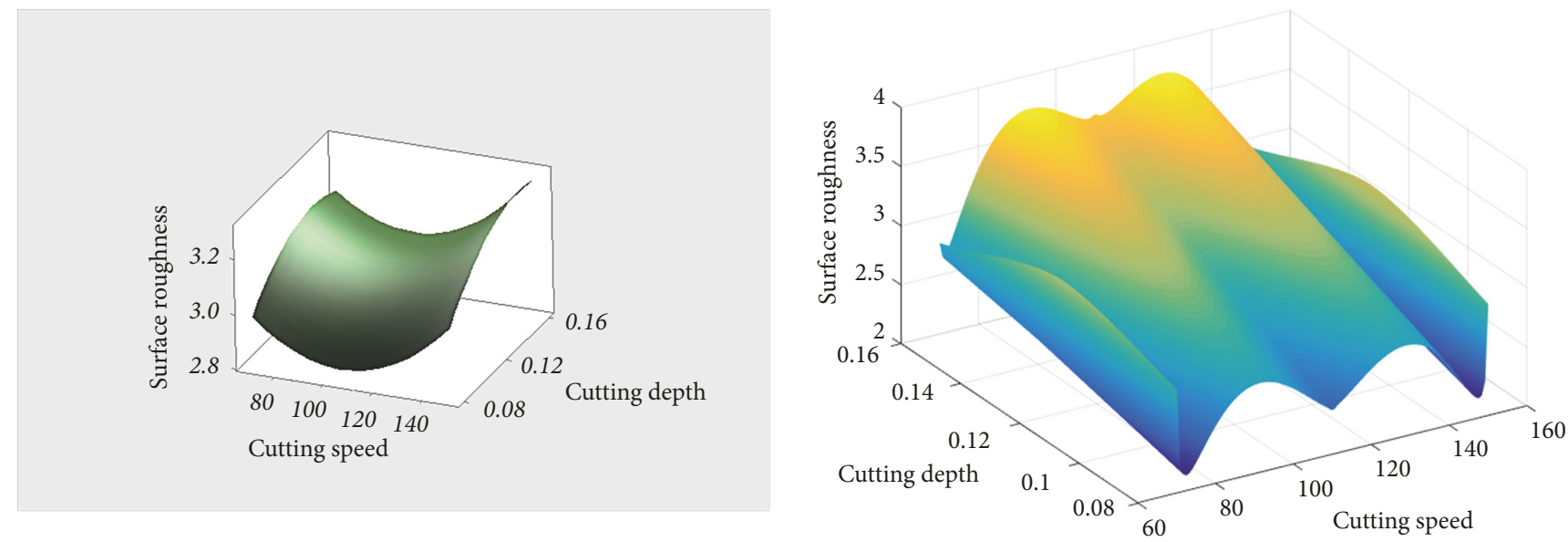

FIGURE 8: Response surface model and surface diagram of surface roughness, cutting speed, and cutting depth.
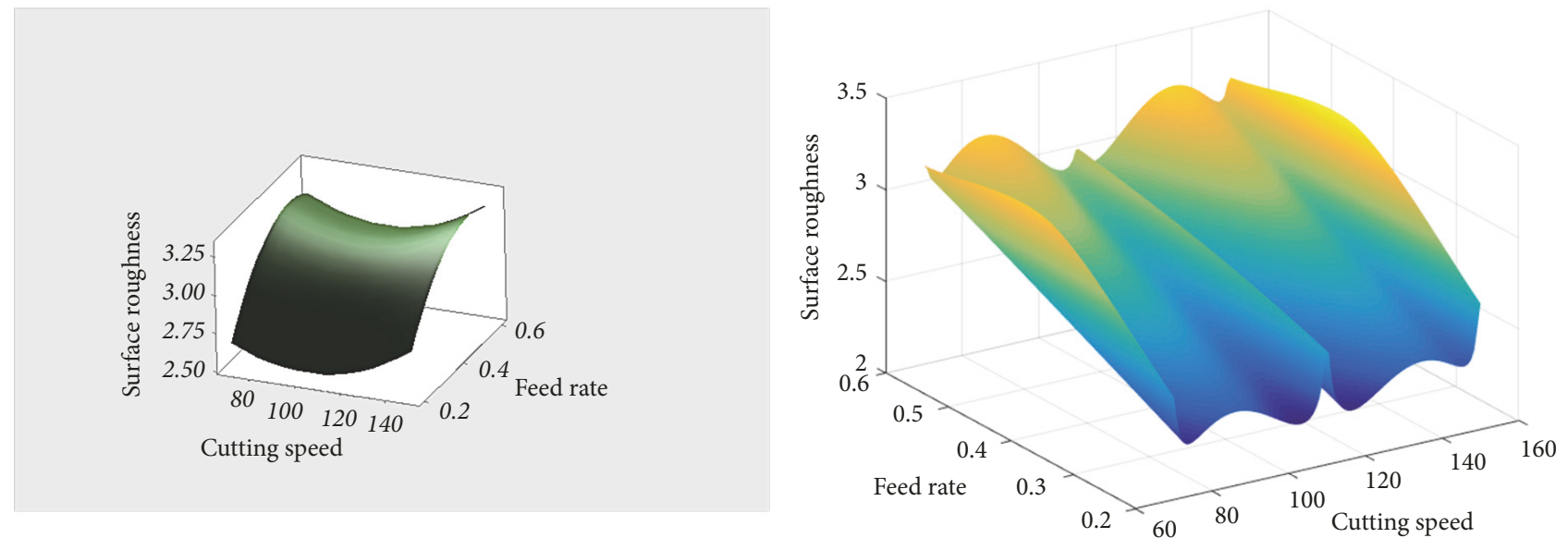

Figure 9: Response surface model and surface diagram of surface roughness, cutting speed, and feed rate.
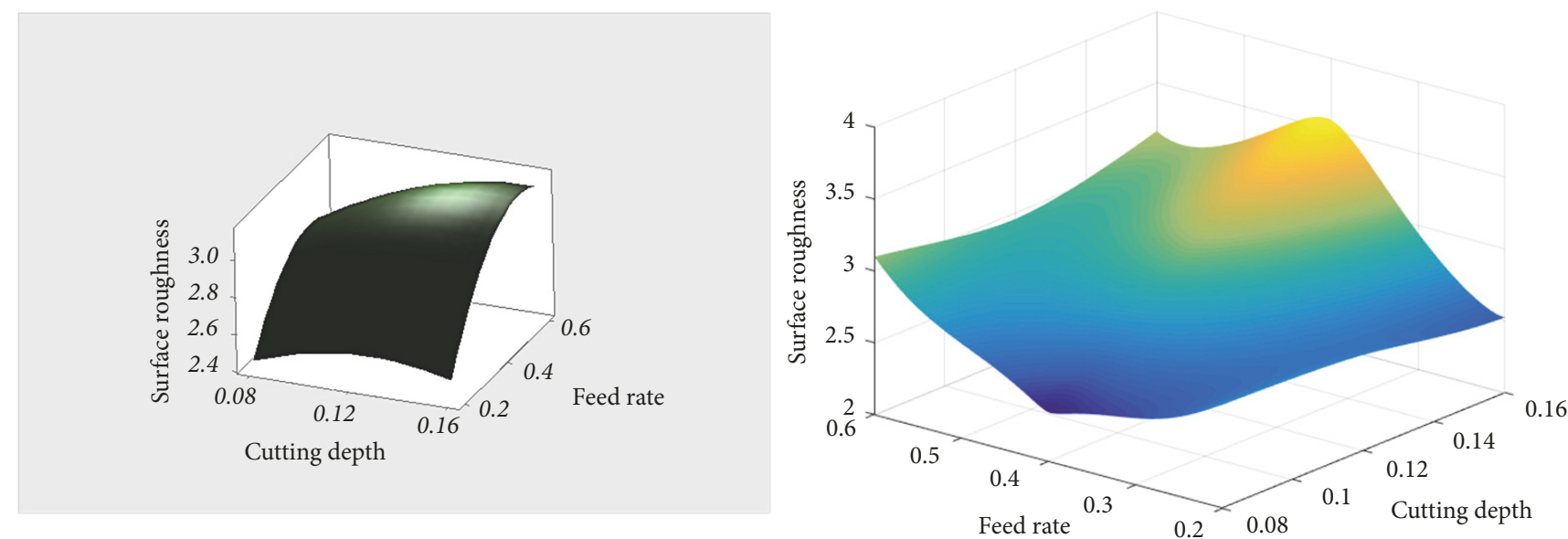

FIGURE 10: Response surface model and surface diagram of surface roughness, cutting depth, and feed rate.

TABLE 7: Constraints.

\begin{tabular}{lcccccc}
\hline & Aims & Lower limit & NTB & Upper limit & Weights & Importance \\
\hline Surface roughness & SIB & 2.503 & 2 & 3.276 & 1 & 1 \\
\hline
\end{tabular}




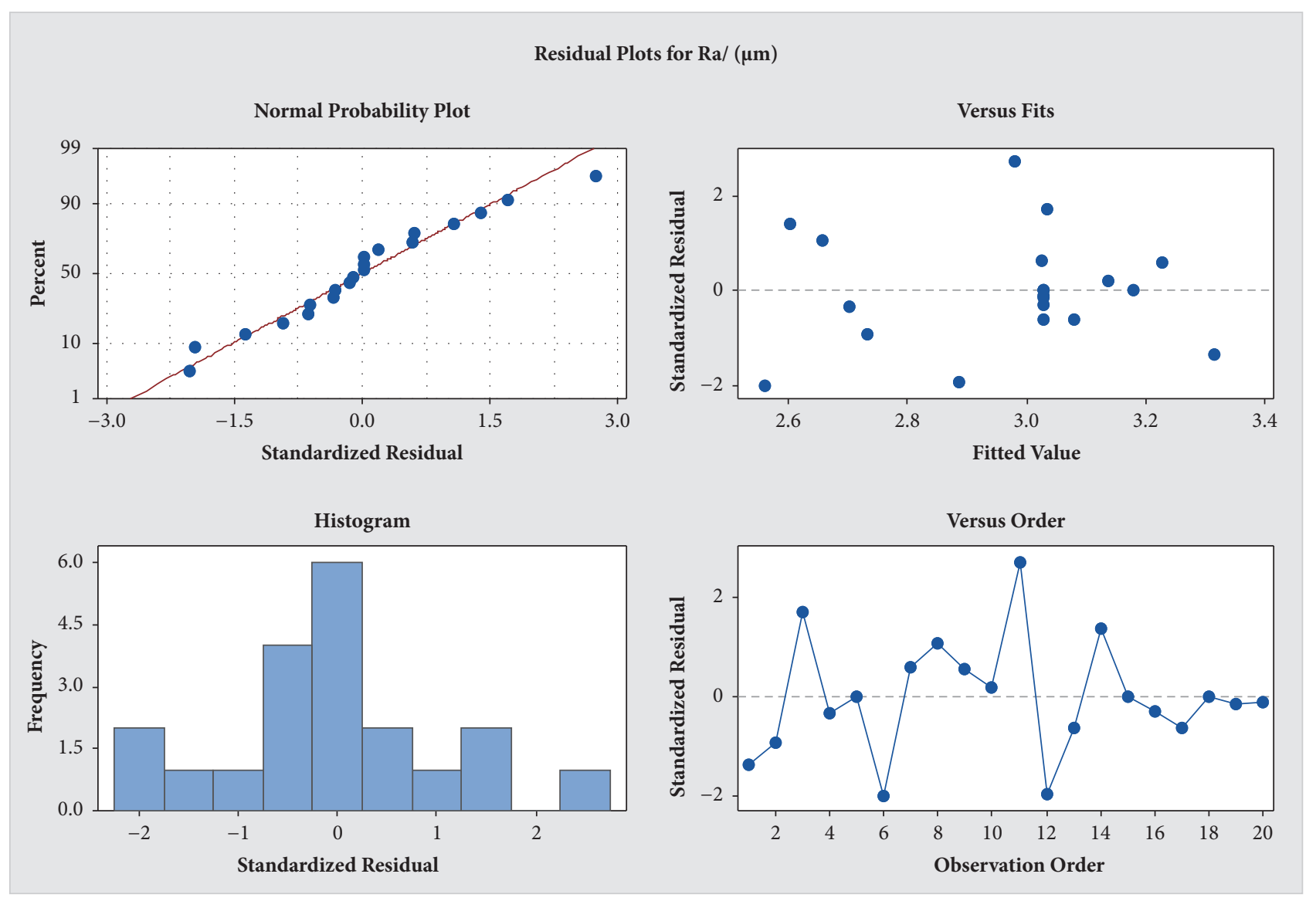

FIGURE 11: Surface roughness residual diagram.

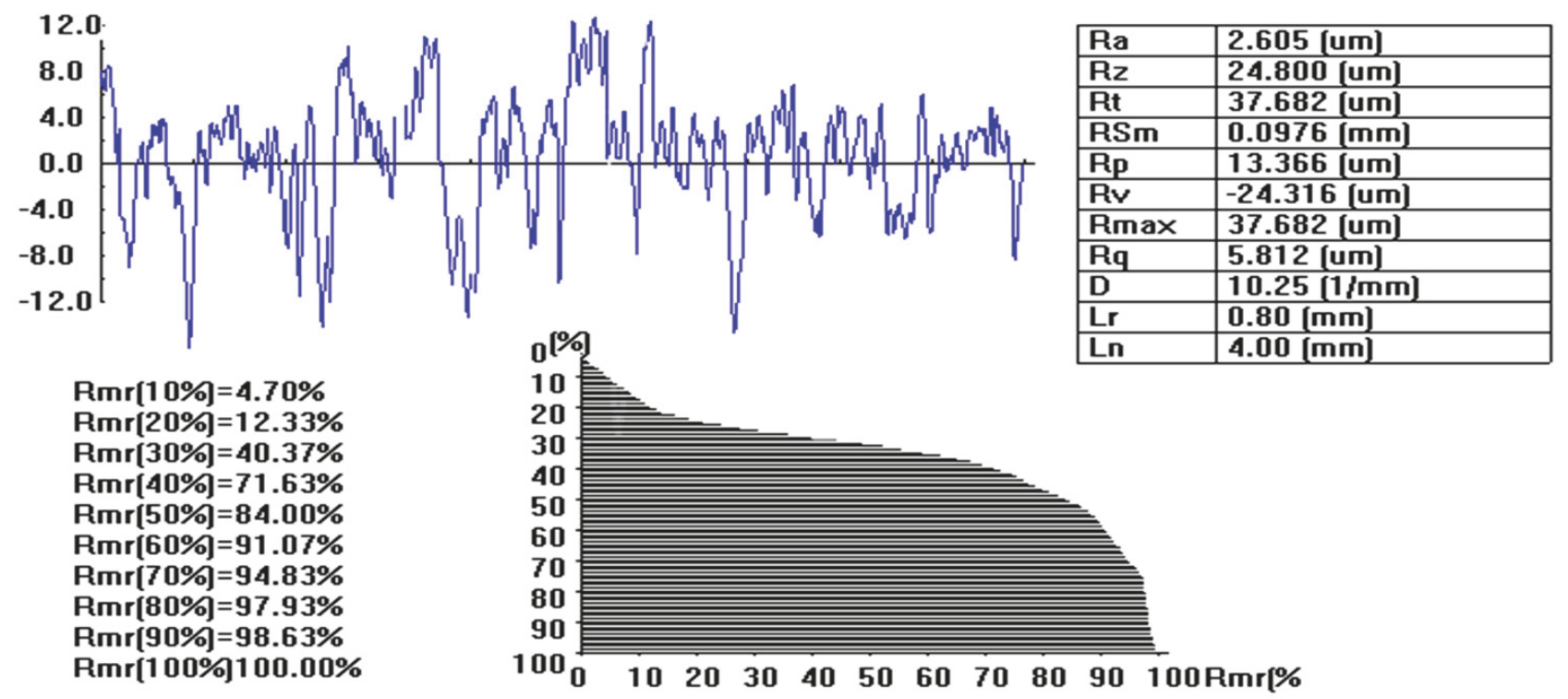

Figure 12: 1Cr18Ni9Ti: cutting speed $85 \mathrm{~m} / \mathrm{min}$, feed rate $0.4 \mathrm{~mm} / \mathrm{r}$, and cutting depth $0.11 \mathrm{~mm}$. 

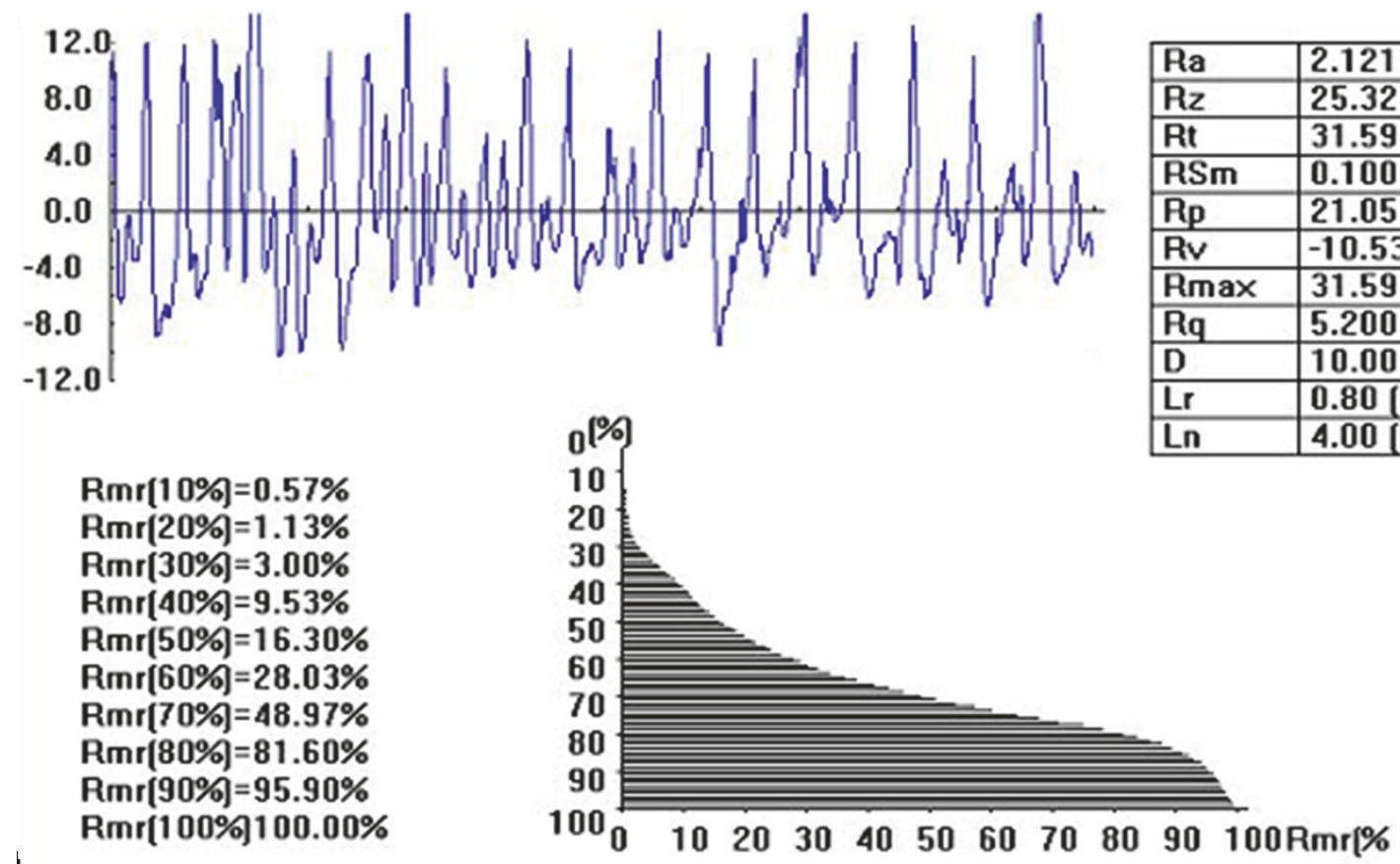

Figure 13: 1Cr18Ni9Ti: cutting speed $92 \mathrm{~m} / \mathrm{min}$, feed rate $0.2 \mathrm{~mm} / \mathrm{r}$, and cutting depth $0.12 \mathrm{~mm}$.

and the best combination of factors that most satisfied the performance index was found. The following results were obtained.

Starting point: $V=70(\mathrm{~m} / \mathrm{min}), a_{p}=0.12(\mathrm{~mm}), f=$ $0.60(\mathrm{~mm} / \mathrm{r})$

Unoptimized model solution: $V=99.0909(\mathrm{~m} / \mathrm{min})$, $a_{p}=0.16(\mathrm{~mm}), f=0.20(\mathrm{~mm} / \mathrm{r})$

Optimized model solution: $V=143.5354(\mathrm{~m} / \mathrm{min}), a_{p}$ $=0.16(\mathrm{~mm}), f=0.20(\mathrm{~mm} / \mathrm{r})$.

From the previous conclusion (discussed in Section 3.2), it can be concluded that the predicted optimal response roughness is $1.85(\mu \mathrm{m})$, the cutting speed is $140(\mathrm{~m} / \mathrm{min})$, cutting depth is $0.16(\mathrm{~mm})$, and feed rate $0.2(\mathrm{~mm} / \mathrm{r})$ can achieve better roughness in the actual machining process, which accords with the optimal region of the model shown in Figures 8-10. Meanwhile, the roughness value of the predicted roughness model (unoptimized equation (6)) is 2.4791 $(\mu \mathrm{m})$, which is $10 \%$ higher than the expected value, as shown in Figure 14(a), and the value of prediction model roughness reached $1.85(\mu \mathrm{m})$ according to regression optimized model of (9), as shown in Figure 14(b); it is about 26\% higher than the expected value, which greatly improved the machined surface quality of stainless steel $1 \mathrm{Cr} 18 \mathrm{Ni}$ Ti.

4.3. Verification Experiment Comparison. We have conducted actual experimental tests on the above theoretical results. We have obtained experimental results for both the optimized model and the unoptimized model (as shown in Figures 15 and 16). It can be seen from the Figures 15 and 16 that the roughness of the optimized model is smaller than the

\begin{tabular}{|l|l|}
\hline$R a$ & $2.121[u m]$ \\
\hline$R z$ & $25.324[u m]$ \\
\hline$R t$ & $31.594[u m]$ \\
\hline$R S m$ & $0.1000[\mathrm{~mm}]$ \\
\hline$R p$ & $21.057[\mathrm{um}]$ \\
\hline$R v$ & $-10.537[\mathrm{um}]$ \\
\hline$R m a \times$ & $31.594[\mathrm{um}]$ \\
\hline$R q$ & $5.200[\mathrm{um}]$ \\
\hline$D$ & $10.00[1 / \mathrm{mm}]$ \\
\hline Lr & $0.80[\mathrm{~mm}]$ \\
\hline Ln & $4.00[\mathrm{~mm}]$ \\
\hline
\end{tabular}

roughness value of the unoptimized model, and both errors are within $8 \%$, but the error of unoptimized model is $2.8 \%$, and the error of optimized model is $7.3 \%$. It is obvious that the model error of the latter is relatively large. We believe that the optimized model removes the insignificant term and leads to an increase in the error of the model.

4.4. Economic Analysis of Machining. The production time of a single part in machining is mainly divided into three parts: preparation time, processing time, and tool replacement time. However, the production cost of a single part is divided into five elements: (1) preparation cost, (2) cutting process cost, (3) tool replacement costs, (4) tooling cost and depreciation cost, and (5) others. From the production time and cost point of view, the life of the tool will affect the processing efficiency, combined with the analysis of the results in Section 3.2; we will optimize the cutting parameters to improve the service life of the tool on the premise of ensuring the roughness. The machining test in this paper is excircle lathing; tool life formula is generally as follows [24]:

$$
T_{0}=\frac{\pi \cdot \mathrm{d} \cdot L \cdot A}{1000 \cdot v \cdot f \cdot a_{p}}
$$

In the formula, $\mathrm{d}$ is the diameter of the workpiece, $\mathrm{L}$ is the length of the workpiece, and $\mathrm{A}$ is the machining allowance. In this paper, $d=451 \mathrm{~mm}, \mathrm{~L}=\pi \mathrm{d}$, and $\mathrm{A}=2 \mathrm{~mm}$. The unit of tool life is hour.

From (10), it can be seen that $f, V$, and $a_{p}$ have influences on the tool life. According to the above conclusions, the influence of the feed amount on the roughness is the largest; in order to ensure the roughness, we first select a suitable feed rate. Under the premise of selecting $f=0.20(\mathrm{~mm} / \mathrm{r})$, the tool 


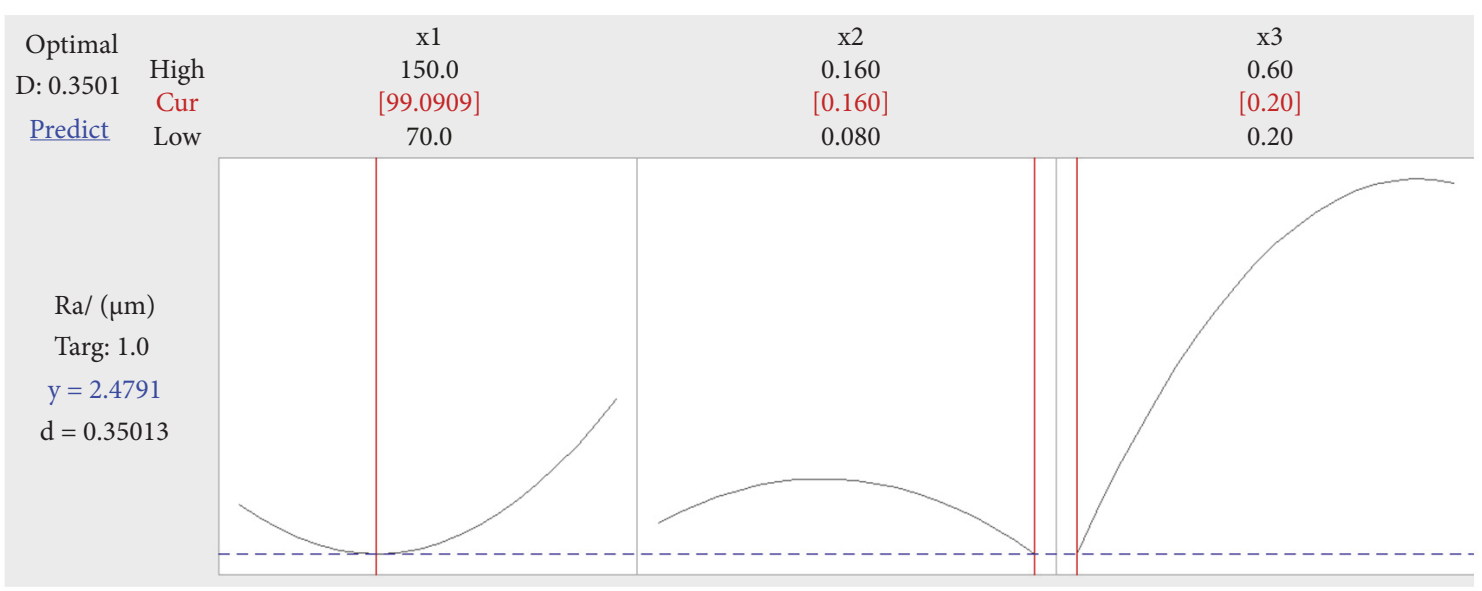

(a) Unoptimized model response optimization analysis

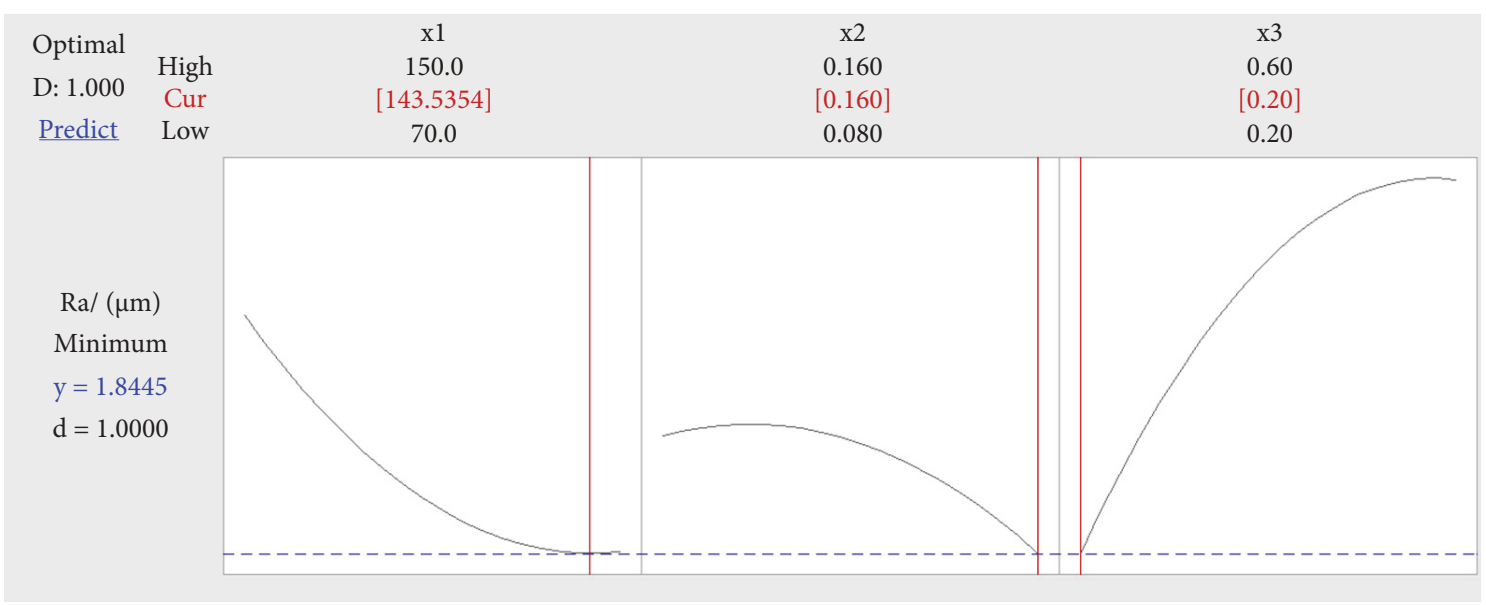

(b) Optimized model response optimization analysis

FIGURE 14: Response optimization analysis.

life is improved by optimizing the cutting speed $\mathrm{v}$ and the cutting depth ap. The influence of the cutting depth is small. Therefore, the main factor influencing the cutting speed is $\mathrm{v}$, and the contour maps of the tool life and roughness are made in combination with (9) and (10), as shown in Figure 17.

As shown in Figure 17(a) which is contour map of $\mathrm{T}_{0}$, $V$, and $a_{p}$, it reflects the relationship between tool life, cutting speed, and cutting depth. Figure $17(\mathrm{~b})$ is contour map of $R_{a}, V$, and $a_{p}$; it reflects the relationship between roughness, cutting speed, and cutting depth. Figure 17(c) is contour map of $\mathrm{T}_{0}, R_{a}, V$, and $a_{p}$; it can be seen that there are a lot of intersections with the tool life contour map when $R_{a}=2.2 \mu \mathrm{m}$ and $R_{a}=1.8 \mu \mathrm{m}$. It shows that there are several sets of cutting parameters that can make the roughness of $2.2 \mu \mathrm{m}$ or $1.8 \mu \mathrm{m}$; however, the tool life of multiple sets of cutting parameters is not the same. We can choose a combination of cutting parameters with long tool life under the premise of ensuring roughness; in this way, tool change time, tool change fees, processing costs, tooling fees, and depreciation fees can be reduced, increasing production efficiency. Therefore, in the actual production combined with the roughness prediction model, tool life formula, and actual processing conditions, select the optimal combination of cutting parameters. Therefore, we can combine the roughness prediction model, tool life formula, and actual machining conditions to select the optimal combination of cutting parameters under actual processing conditions.

4.5. Discussion. In this paper, the Taguchi design method was used to design the turning test, and the roughness model prediction model was constructed by using the central composite surface design in the RSM. The response surface method is not as complex as the neural network algorithm, and it is easily migrated to predictive models in other cases where large amounts of data cannot be obtained. Compared to the self-adaptive neural network model in [25], this model does not need to do a lot of experiments. At the same time, this paper optimizes the model again and has higher prediction accuracy and smaller error than the paper [26]. Combined with the surface roughness prediction model and the tool life contour map, the optimal cutting parameters can be selected in combination with the production conditions in the actual production. Three factors were considered: cutting speed, feed rate, and cutting depth. The least squares method 


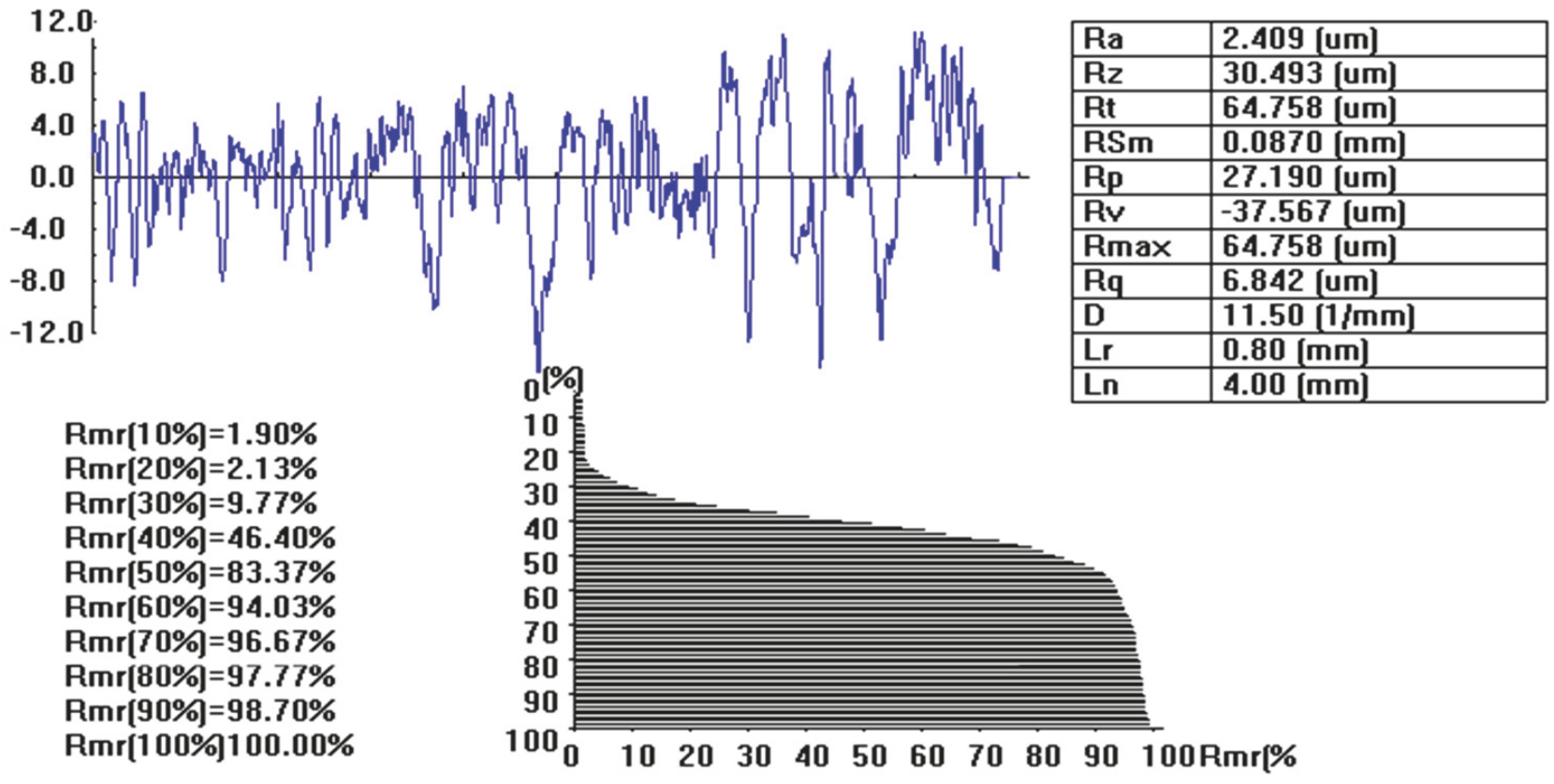

FIGURE 15: Unoptimized model test results.

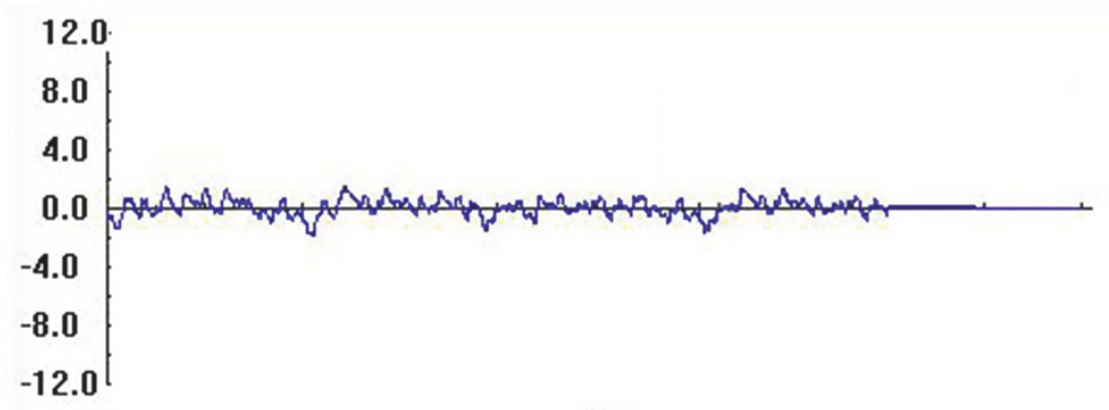

$\operatorname{Rmr}[10 \%=1.33 \%$

$\operatorname{Rmr}[20 \%]=2.57 \%$

$\operatorname{Rmr}[30 \%=4.97 \%$

$\operatorname{Rmr}[40 \%]=7.33 \%$

$\operatorname{Rmr}[50 \%=20.30 \%$

$\operatorname{Rmr}[60 \%]=89.00 \%$

$\operatorname{Rmr}(70 \%=93.30 \%$

$\operatorname{Rmr}[\mathbf{8 0 \%}=95.87 \%$

$\operatorname{Rmr}[\mathbf{9 0 \%}=\mathbf{9 7 . 4 3 \%}$

$\operatorname{Rmr}[100 \% 100.00 \%$

\begin{tabular}{|l|l|}
\hline$R a$ & $1.713[\mathrm{um}]$ \\
\hline$R z$ & $4.759[\mathrm{um}]$ \\
\hline$R t$ & $15.445[\mathrm{um}]$ \\
\hline$R S m$ & $0.1250[\mathrm{~mm}]$ \\
\hline$R p$ & $8.224[\mathrm{um}]$ \\
\hline$R v$ & $-7.221[\mathrm{um}]$ \\
\hline$R m a \times$ & $15.445[\mathrm{um}]$ \\
\hline$R q$ & $1.192[\mathrm{um}]$ \\
\hline$D$ & $8.00[1 \mathrm{~mm}]$ \\
\hline $\mathrm{Lr}$ & $0.80[\mathrm{~mm}]$ \\
\hline $\mathrm{Ln}$ & $4.00[\mathrm{~mm}]$ \\
\hline
\end{tabular}

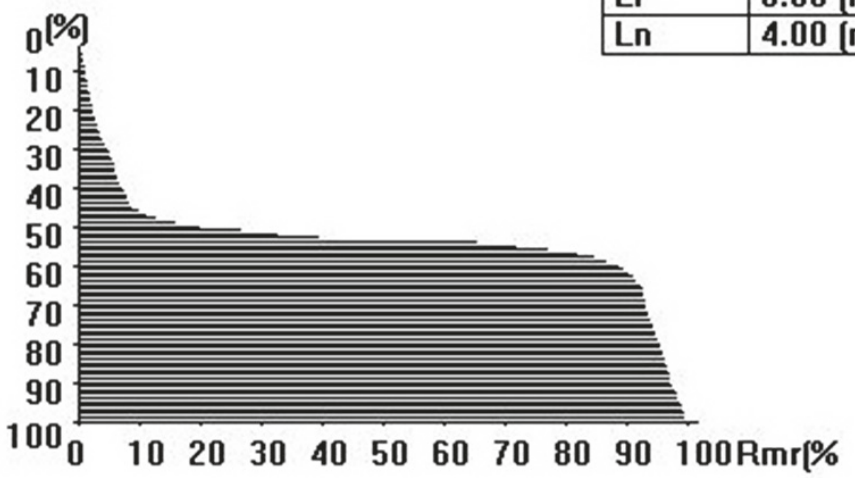

FIGURE 16: Optimized model test results.

was used to estimate the regression coefficients, and the regression equation was curve fitted. At the same time, the predictive model and response surface design were tested and optimized, respectively. The response surface map and Matlab 3D surface map were established. The relationship between the factors and the accuracy of the prediction model were analyzed and the process parameters were optimized.

\section{Conclusion}

(1) The response surface method can effectively model the nonlinear cutting parameters that have many influencing factors in the lathe turning process, and the model is significant. The reliability analysis and verification test show that the surface roughness analysis model of stainless steel $1 \mathrm{Cr} 18 \mathrm{Ni} 9 \mathrm{Ti}$ 


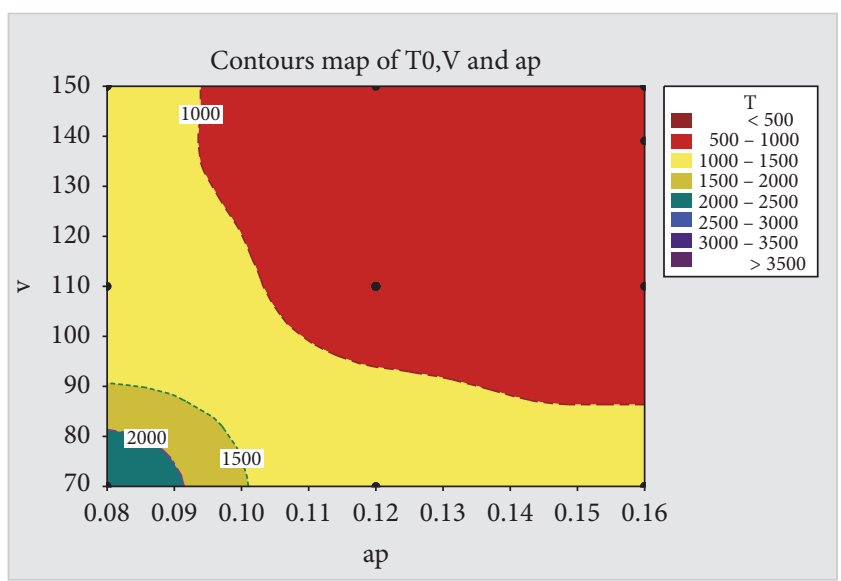

(a) Contours map of $\mathrm{T}_{0}, V$, and $a_{p}$

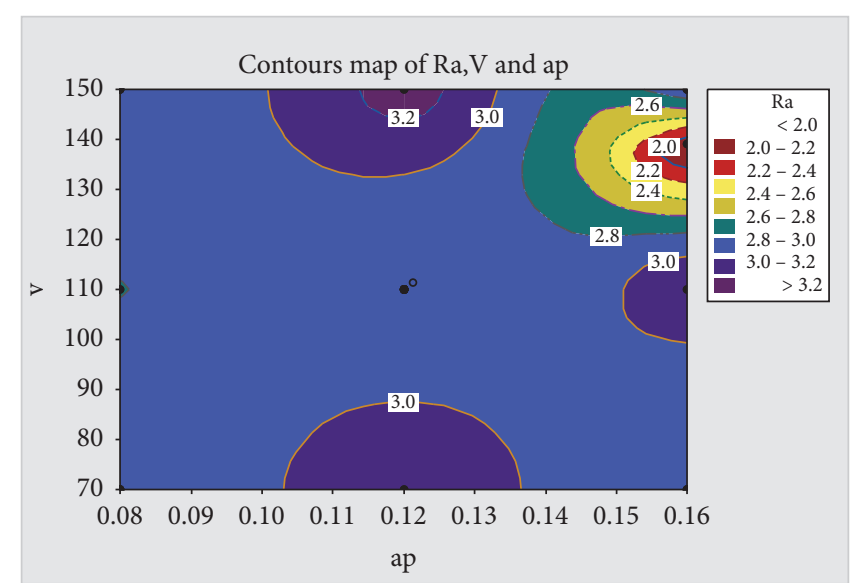

(b) Contours map of Ra, $V$, and $a_{p}$

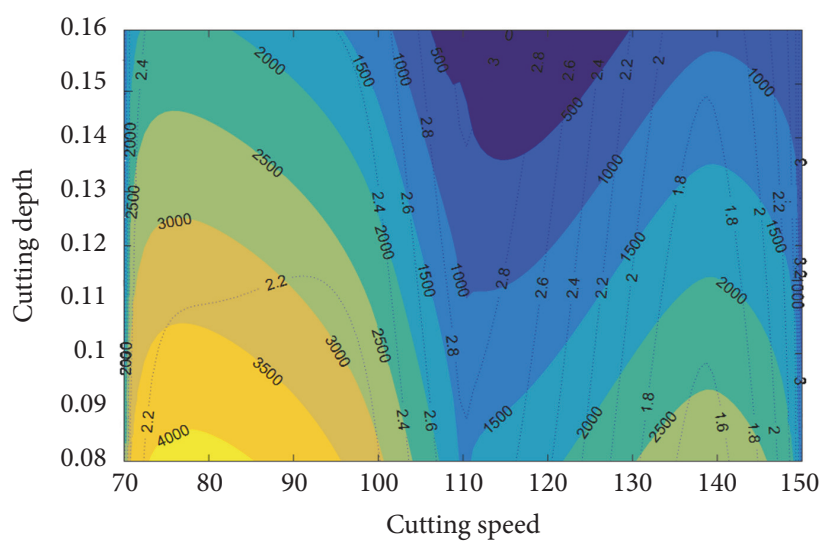

(c) Contour map with fixed feed rate

FIgURE 17: Tool life and roughness contour map.

established by second-order response surface method is reliable. It can provide some experimental evidences for the control of $1 \mathrm{Cr} 18 \mathrm{Ni} 9 \mathrm{Ti}$ surface roughness in the range of experimental parameters. Meanwhile, we found that the influence of feed rate on the surface roughness is the most significant, the cutting depth is the second, and the influence of cutting speed is smallest among the three factors that affect the turning surface roughness of stainless steel $1 \mathrm{Cr} 18 \mathrm{Ni9Ti}$ through the prediction model and experimental analysis.

(2) The surface roughness of stainless steel workpieces can be effectively controlled through reasonable selection of process parameters; two sets of data were selected for comparison experiments under the conditions of the prediction model in the paper. We found that a lower surface roughness value can be obtained when $V=143.5354(\mathrm{~m} / \mathrm{min}), a_{p}=0.16$ $(\mathrm{mm})$, and $f=0.20(\mathrm{~mm} / \mathrm{r})$; the value is less than the value of unoptimized model parameter $\left(V=99.0909(\mathrm{~m} / \mathrm{min}), a_{p}\right.$ $=0.16(\mathrm{~mm})$, and $f=0.20(\mathrm{~mm} / \mathrm{r}))$. So we obtained a set of optimal parameters for turning stainless steel: cutting speed $140(\mathrm{~m} / \mathrm{min})$, cutting depth $0.16(\mathrm{~mm})$, and feed rate 0.2 $(\mathrm{mm} / \mathrm{r})$. The surface roughness can be effectively controlled at about $1.85(\mu \mathrm{m})$.

(3) We can see that there are many sets of cutting parameters under the same roughness through the analysis of the contour map of the roughness and tool life; these parameters directly affect the service life of the tool. Under the premise of ensuring roughness, the processing parameters that can maximize the tool life can be selected according to contour maps, processing costs can be reduced, and production efficiency can be increased. It has guiding significance for economical processing.

\section{Data Availability}

The data used to support the findings of this study are included within the article.

\section{Conflicts of Interest}

The authors declare that there are no conflicts of interest regarding the publication of this paper.

\section{Acknowledgments}

The research is funded partially by the National Key Research and Development Program of China (2016YFD0701103), Science and Technology Foundation of Outstanding Young 
Talents of Nanjing Agricultural University (YQ201605), and funding of the Fundamental Research Funds for the Central Universities (KYZ201760).

\section{References}

[1] D. S. C. Jayswal and M. Taufik, "Modeling And Analysis Of The Surface Roughness And Geometrical Error Using Taguchi And Response Surface Methodology," International Journal of Engineering Science \& Technology, vol. 3, no. 7, p. 5809, 2011.

[2] Z. Long, X. Wang, and H. Wang, "Analysis of Variance about Influence Factor on Surface Roughness of Difficult-to-cut Material in High Speed Machining Process," Tool Engineering, vol. 1, pp. 26-29, 2005.

[3] Z. Fu, "Importance of surface roughness and correct acquisition method," Occupation, vol. 17, no. 53, 2007.

[4] F. Ling, "Effect of Cutting Parameters on Surface Roughness of Stainless Steel," Tool Technology, vol. 41, no. 7, pp. 79-80, 2007.

[5] P. Suresh V S, P. Rao V, and G. Deshmukh S, "A genetic algorithmic approach for optimization of surface roughness prediction model," Machining Science \& Technology, vol. 42, no. 6, pp. 675-680, 2002.

[6] Y. Hao and Y. Liu, "Analysis of milling surface roughness prediction for thin-walled parts with curved surface," The International Journal of Advanced Manufacturing Technology, vol. 93, no. 5-8, pp. 2289-2297, 2017.

[7] B. H. Kim and C. N. Chu, "Texture prediction of milled surfaces using texture superposition method," Computer-Aided Design, vol. 31, no. 8, pp. 485-494, 1999.

[8] A. K. Verma, S. L. Holcomb, P. Blessner, D. Tilman, and W. F. Johnston, "Parametric Study of Surface Finish in End Milling Using Robust Design Techniques," in Proceedings of the ASME International Mechanical Engineering Congress and Exposition, pp. 31-37, Washington, DC, USA, 2003.

[9] C.-C. Chen, N.-M. Liu, K.-T. Chiang, and H.-L. Chen, "Experimental investigation of tool vibration and surface roughness in the precision end-milling process using the singular spectrum analysis," The International Journal of Advanced Manufacturing Technology, vol. 63, no. 5-8, pp. 797-815, 2012.

[10] Z. Li, W. Ding, C. Liu, and H. Su, "Prediction of grinding temperature of PTMCs based on the varied coefficients of friction in conventional-speed and high-speed surface grinding," The International Journal of Advanced Manufacturing Technology, vol. 90, no. 5-8, pp. 2335-2344, 2017.

[11] Z. Lu and M. Wang, "Predictive modeling of surface roughness and cutting parameters optimization in ultra-precision turning based on genetic algorithm," Journal of Mechanical Engineering, vol. 41, no. 11, pp. 158-162, 2005.

[12] J.-S. Chen, Y.-K. Huang, and M.-S. Chen, "A study of the surface scallop generating mechanism in the ball-end milling process," The International Journal of Machine Tools and Manufacture, vol. 45, no. 9, pp. 1077-1084, 2005.

[13] J. C. Chen and M. Savage, "A fuzzy-net-based multilevel inprocess surface roughness recognition system in milling operations," The International Journal of Advanced Manufacturing Technology, vol. 17, no. 9, pp. 670-676, 2001.

[14] L. Yang, J. C. Chen, H. Chow, and C. Lin, "Fuzzy-nets-based in-process surface roughness adaptive control system in endmilling operations," The International Journal of Advanced Manufacturing Technology, vol. 28, no. 3-4, pp. 236-248, 2006.
[15] I. Abu-Mahfouz, O. El Ariss, A. H. M. Esfakur Rahman, and A. Banerjee, "Surface roughness prediction as a classification problem using support vector machine," The International Journal of Advanced Manufacturing Technology, vol. 92, no. 1-4, pp. 803-815, 2017.

[16] S. Kalidass and P. Palanisamy, "Prediction of Surface Roughness for AISI 304 Steel with Solid Carbide Tools in End Milling Process Using Regression and ANN Models," Arabian Journal for Science and Engineering, vol. 39, no. 11, pp. 8065-8075, 2014.

[17] J. Chenzhe, L. Jiangnan, J. Zenghui et al., "Prediction Model of Micro Milling Surface Roughness Based on Artificial Neural Network," Tool Technology, vol. 49, no. 8, pp. 92-95, 2015.

[18] Y. Qu, Y. Liang, and H. Wang, "Prediction of precision turning surface roughness based on genetic algorithm toolbox," Tool Technology, vol. 41, no. 3, pp. 22-25, 2007.

[19] P. S. Desale and R. S. Jahagirdar, "Modeling of Hardened Die Steel Böhler K340 for Prediction of Surface Roughness in High Speed End Milling using Adaptive Neuro- Fuzzy Inference System," International Journal of Applied Engineering Research, vol. 7, no. 11, p. 1297, 2012.

[20] K. Zhang, "Cause Analysis of Turning Surface Roughness and Measures to Reduce," Coal mining machinery, vol. 34, no. 5, pp. 166-168, 2013.

[21] X. H. X. Zu, "Xiaoling Prediction Model and Parameter Optimization of Surface Roughness in Machining," Manufacturing Automation, vol. 20, pp. 39-42, 2014.

[22] S. Kim, "A Review on the Taguchi Method and Its Alternatives for Dynamic Robust Design," Journal of Korean Institute of Industrial Engineers, vol. 39, no. 5, pp. 351-360, 2013.

[23] X. Xu, Y. Jiang, and H. P. Lee, "Multi-objective optimal design of sandwich panels using a genetic algorithm," Engineering Optimization, vol. 49, no. 10, pp. 1665-1684, 2017.

[24] J. Lu and J. Sun, Metal Cutting Principles and Tools, Version 5, Machinery Industry Press, 2011.

[25] P. S. Desale and R. S. Jahagirdar, "Modeling of Hardened Die Steel Böhler K340 for Prediction of Surface Roughness in High Speed End Milling using Adaptive Neuro- Fuzzy Inference System," International Journal of Applied Engineering Research, vol. 7, no. 11, pp. 1297-1304, 2012.

[26] J. Qi and B. Yan, "Research on Surface Roughness Prediction Model Based on Response Surface Method," Mechanical Design and Manufacturing Engineering, vol. 1, pp. 73-76, 2014. 


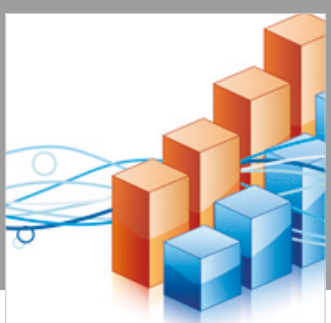

Advances in

Operations Research

\section{-n-m}
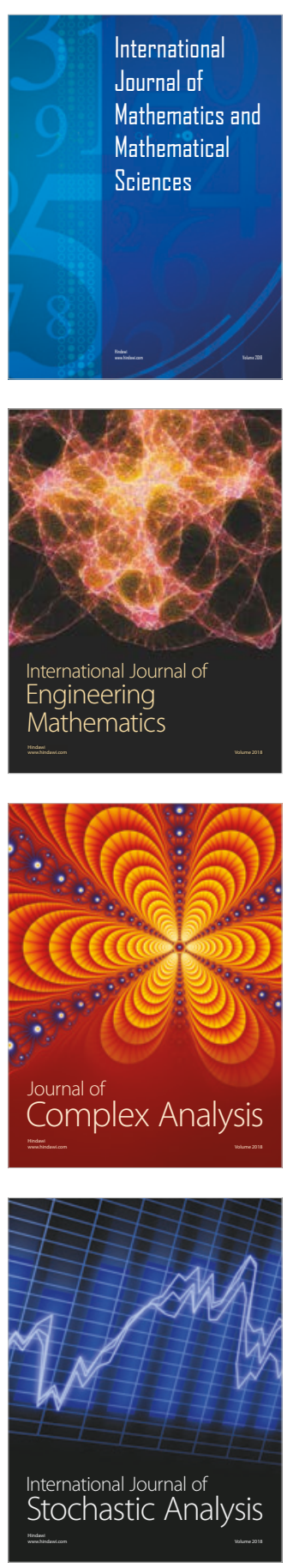
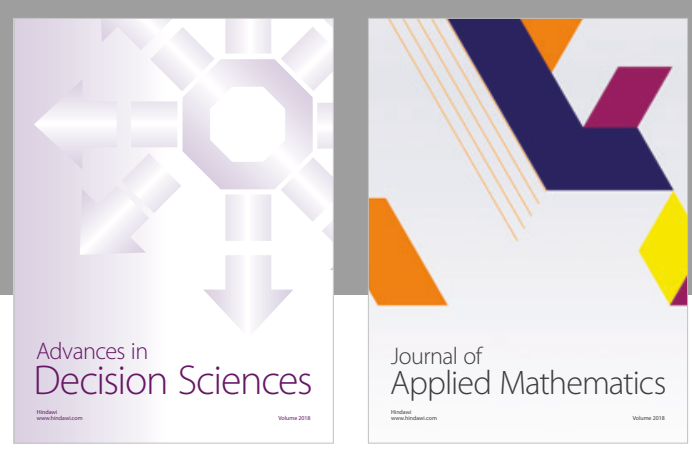

Journal of

Applied Mathematics
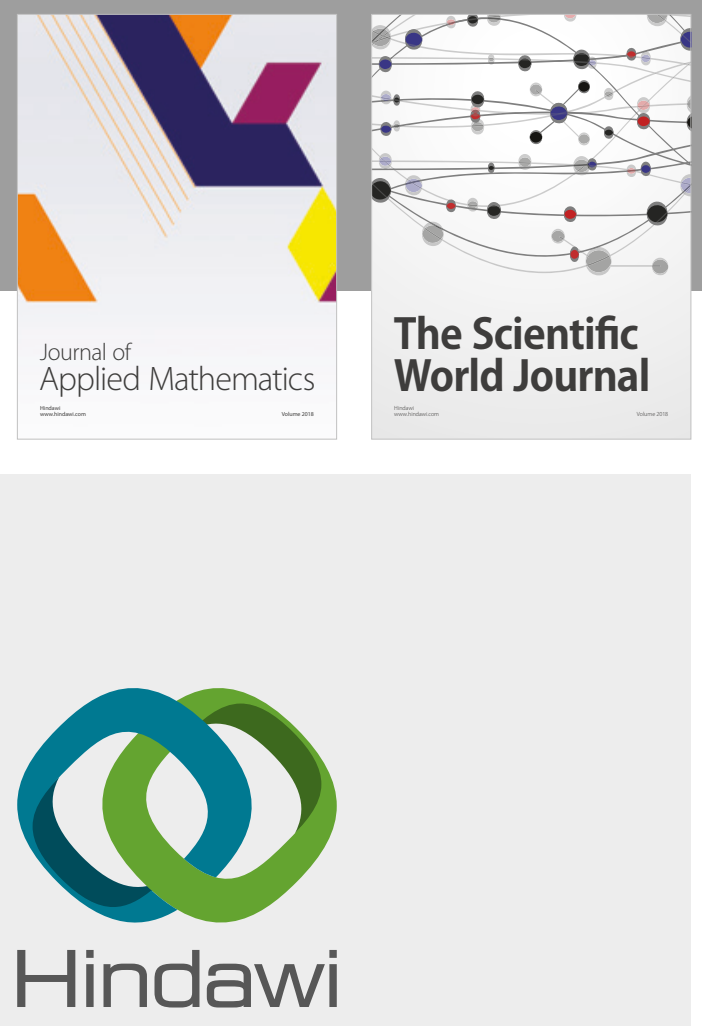

Submit your manuscripts at

www.hindawi.com

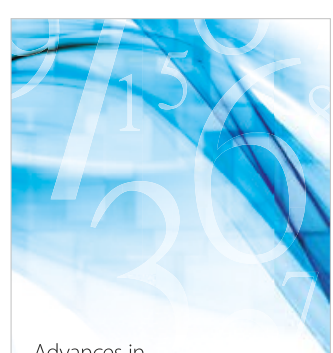

Advances in
Numerical Analysis
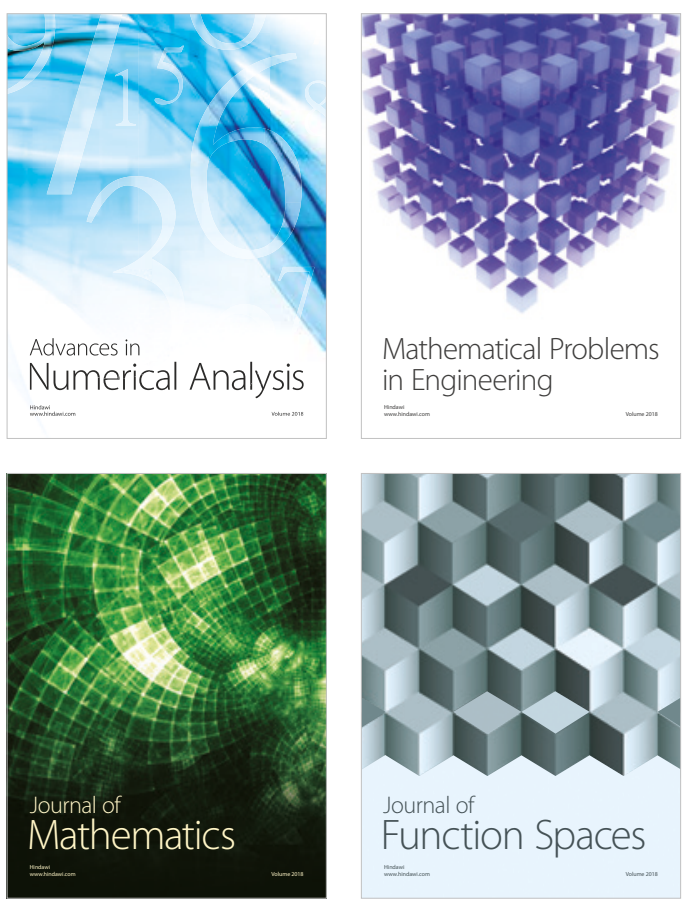

Mathematical Problems in Engineering

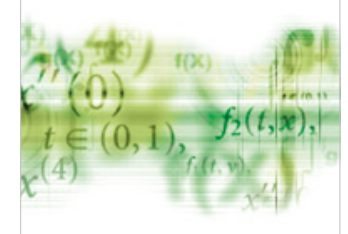

International Journal of

Differential Equations

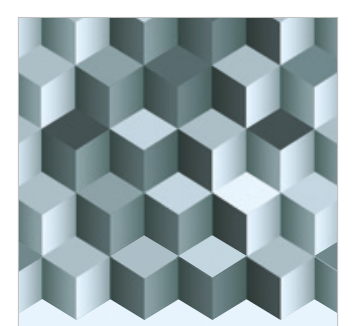

Journal of

Function Spaces

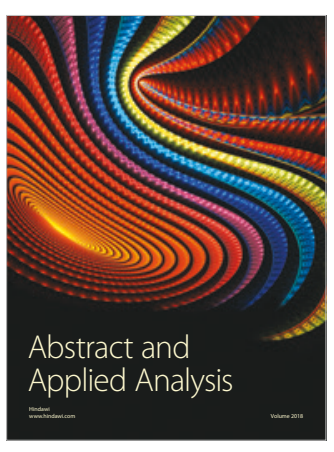

The Scientific

World Journal

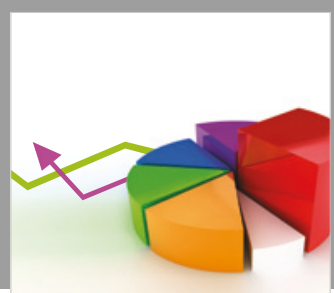

Journal of

Probability and Statistics
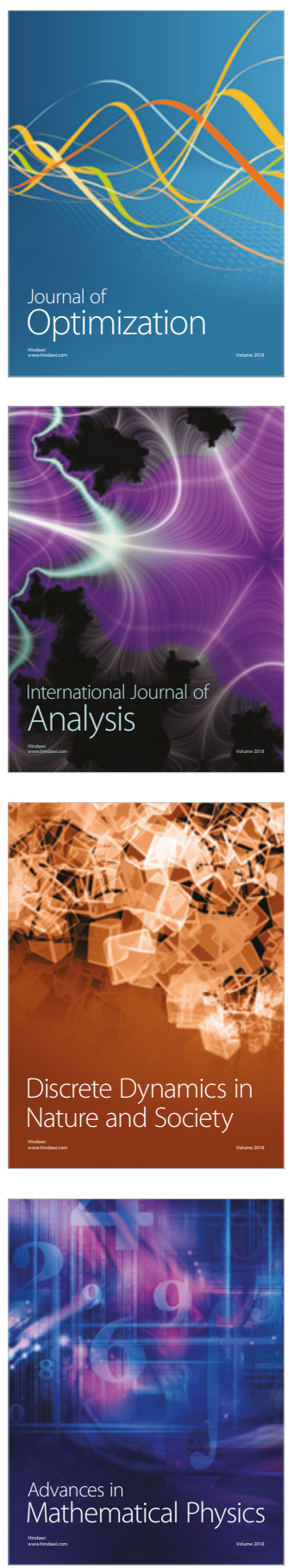